\title{
Extensive loss of Wnt genes in Tardigrada
}

\author{
Raul A. Chavarria, Mandy Game, Briana Arbelaez, Chloe Ramnarine, Zachary K. Snow and Frank W. Smith*
}

\begin{abstract}
Background: Wnt genes code for ligands that activate signaling pathways during development in Metazoa. Through the canonical Wnt (cWnt) signaling pathway, these genes regulate important processes in bilaterian development, such as establishing the anteroposterior axis and posterior growth. In Arthropoda, Wnt ligands also regulate segment polarity, and outgrowth and patterning of developing appendages. Arthropods are part of a lineage called Panarthropoda that includes Onychophora and Tardigrada. Previous studies revealed potential roles of Wnt genes in regulating posterior growth, segment polarity, and growth and patterning of legs in Onychophora. Unlike most other panarthropods, tardigrades lack posterior growth, but retain segmentation and appendages. Here, we investigated Wnt genes in tardigrades to gain insight into potential roles that these genes play during development of the highly compact and miniaturized tardigrade body plan.
\end{abstract}

Results: We analyzed published genomes for two representatives of Tardigrada, Hypsibius exemplaris and Ramazzottius varieornatus. We identified single orthologs of Wnt4, Wnt5, Wnt9, Wnt11, and WntA, as well as two Wnt16 paralogs in both tardigrade genomes. We only found a Wnt2 ortholog in H. exemplaris. We could not identify orthologs of Wnt1, Wnt6, Wnt7, Wnt8, or Wnt10. We identified most other components of cWnt signaling in both tardigrade genomes. However, we were unable to identify an ortholog of arrow/Lrp5/6, a gene that codes for a Frizzled co-receptor of Wnt ligands. Additionally, we found that some other animals that have lost several Wnt genes and are secondarily miniaturized, like tardigrades, are also missing an ortholog of arrow/Lrp5/6. We analyzed the embryonic expression patterns of Wnt genes in H. exemplaris during developmental stages that span the establishment of the AP axis through segmentation and leg development. We detected expression of all Wnt genes in H. exemplaris besides one of the Wnt16 paralogs. During embryo elongation, expression of several Wnt genes was restricted to the posterior pole or a region between the anterior and posterior poles. Wnt genes were expressed in distinct patterns during segmentation and development of legs in $H$. exemplaris, rather than in broadly overlapping patterns.

Conclusions: Our results indicate that Wnt signaling has been highly modified in Tardigrada. While most components of cWnt signaling are conserved in tardigrades, we conclude that tardigrades have lost Wnt1, Wnt6, Wnt7, Wnt8, and Wnt10, along with arrow/Lrp5/6. Our expression data may indicate a conserved role of Wnt genes in specifying posterior identities during establishment of the AP axis. However, the loss of several Wnt genes and the distinct expression patterns of Wnt genes during segmentation and leg development may indicate that combinatorial interactions among Wnt genes are less important during tardigrade development compared to many other animals. Based on our results, and comparisons to previous studies, we speculate that the loss of several Wnt genes in Tardigrada may be related to a reduced number of cells and simplified development that accompanied miniaturization and anatomical simplification in this lineage.

Keywords: Wnt signaling, Tardigrada, Miniaturization, Posterior growth, Panarthropoda original author(s) and the source, provide a link to the Creative Commons licence, and indicate if changes were made. The images or other third party material in this article are included in the article's Creative Commons licence, unless indicated otherwise in a credit line to the material. If material is not included in the article's Creative Commons licence and your intended use is not permitted by statutory regulation or exceeds the permitted use, you will need to obtain permission directly from the copyright holder. To view a copy of this licence, visit http://creativecommons.org/licenses/by/4.0/. The Creative Commons Public Domain Dedication waiver (http://creativeco $\mathrm{mmons}$.org/publicdomain/zero/1.0/) applies to the data made available in this article, unless otherwise stated in a credit line to the data. 


\section{Background}

Wnt genes are a group of paralogous ligand-coding genes that play instrumental roles in regulating animal development through both canonical and non-canonical Wnt signaling pathways [1-6]. One important role of Wnt genes is regulating the development of primary body axes [7-14]. In Bilateria, the anteroposterior (AP) body axis is the primary body axis. In many bilaterians, polarized expression of Wnt genes establishes the AP axis by promoting posterior identity and suppressing anterior identity [9, 15-19]. After establishing the AP axis in many bilaterians, canonical Wnt (cWnt) signaling then regulates posterior growth [20-29]. Establishing the AP axis and regulating posterior growth are most likely ancestral functions of Wnt genes in Bilateria $[9,20]$. Therefore, Wnt genes may have played a key role in the origin of the AP axis of bilaterians [30].

Wnt genes also regulate development of body plan characteristics at more narrow taxonomic scales within Bilateria. For example, studies of the $W n t 1$ ortholog wingless $(w g)$ have played a key part in deciphering the development of the segmented body plans of the hyperdiverse Arthropoda. In Drosophila melanogaster, wg participates in the segment polarity network with engrailed (en) hedgehog (hh), and other genes [31-34]. This network is required for segment formation and intrasegmental patterning in arthropods. Later, $w g$ initiates growth of the proximodistal $(\mathrm{PD})$ axis in legs and other appendage types and then specifies ventral fate in these appendages [35-42]. These functions of $w g$ are highly conserved across Arthropoda, although $w g$ most likely does not function as a segment polarity gene in spiders [35, 4358]. In arthropods, other Wnt genes are expressed in patterns that resemble $w g$ expression, indicating that several Wnt genes may be acting redundantly or combinatorially to regulate development in this lineage [3, 58-63]. Wnt genes have also been studied in two species of Onychophora [28, 64-66], the likely sister group of Arthropoda [67-69]. The segment polarity network is most likely conserved in onychophorans, in which it may regulate intrasegmental patterning, but is unlikely to play a role in segment formation [64-66, 70]. Additionally, Wnt genes appear to play roles in the segmentation process and during appendage development in onychophorans that are not characteristic of arthropods [28].

Several lines of evidence suggest that Tardigrada represents the outgroup of an arthropod+onychophoran lineage in a monophyletic Panarthropoda [67, 68, 71], although other relationships have been recovered in some analyses [69, 72], making studies of tardigrades critical for resolving where in panarthropod phylogeny important roles of Wnt genes evolved. Additionally, the unique body plan and developmental mode of Tardigrada raises intriguing questions about the roles of Wnt genes in this lineage. Tardigrades have a highly compact body plan composed of a single-segment head and four leg bearing trunk segments. This compact body plan evolved in conjunction with miniaturization [73, 74]. Embryonic expression analyses of Hox genes and other AP axis patterning genes in the tardigrade Hypsibius exemplaris revealed that tardigrades have lost a mid-trunk region $[75,76]$. The mid-trunk region that is missing in tardigrades develops by posterior growth in other panarthropods [75, 77]. Tardigrades have lost posterior growth; all segments develop nearly simultaneously in these animals [78-81]. Additionally, the proximodistal (PD) axis of $H$. exemplaris legs is missing an intermediate domain defined by dachshund expression that is found in onychophorans, arthropods, and other animals [82]. The fact that Wnt genes regulate the development of both the AP axis and $\mathrm{PD}$ axis in other animals suggests that the evolution of the compact tardigrade body plan may be associated with modifications to the functions of Wnt genes in Tardigrada.

Here, we present the first study of Wnt genes in Tardigrada. We discovered that several Wnt genes and arrow, an ortholog of $\operatorname{Lrp} 5$ and Lrp6 in vertebrates, which codes for a co-receptor of Wnt ligands, have been lost in the tardigrade lineage. Based on comparisons to other metazoan genomes, it appears that the loss of several Wnt genes and arrow/Lrp $5 / 6$ are common features of genome evolution in secondarily miniaturized animals, like tardigrades. Expression patterns of Wnt genes in $H$. exemplaris embryos suggest that these genes play roles during establishment of the AP axis, segmentation, endomesodermal development, foregut development, and leg development. Interestingly, Wnt genes exhibit distinct expression patterns during segmentation and leg development, rather than similar expression patterns like in many other animals. This fact, along with the extensive loss of Wnt genes in Tardigrada, may indicate that tardigrade Wnt genes exhibit reduced combinatorial interactions compared to some other animals. We suggest that the extensive loss of Wnt genes in Tardigrada is associated with miniaturization and the associated reduction of cell number and simplified developmental mechanisms that accompany this process.

\section{Results}

\section{Phylogenetic and genomic analyses of tardigrade Wnt genes}

We identified eight candidate Wnt genes in the H. exemplaris genome and seven Wnt genes in the genome of $R$. varieornatus by BLAST search. We confirmed that all candidate Wnt genes encode a Wnt superfamily domain by $\mathrm{CD}$-search analysis [83]. Our phylogenetic analyses 
revealed that both $H$. exemplaris and $R$. varieornatus possess orthologs of Wnt4, Wnt5, Wnt9, Wnt11, Wnt16, and WntA (Fig. 1; Table 1; Additional file 1: Fig. S1). These species each had two paralogs of Wnt16, which we refer to as Wnt16A and Wnt16B. Additionally, H. exemplaris possesses an ortholog of Wnt2. We did not detect orthologs of Wnt1, Wnt6, Wnt7, Wnt8, and Wnt10-Wnt genes that would be predicted to be present in tardigrade genomes $[2,3,5,6,84]$. Next, we investigated the arrangement of Wnt genes in the genomes of $H$. exemplaris and $R$. varieornatus $[71,85]$. In $H$. exemplaris, all Wnt genes were found on unique scaffolds (Table 1). Scaffolds with Wnt genes ranged in length from 95,696 to $1,074,739 \mathrm{nt}$ in this species. In $R$. varieornatus, scaffolds with Wnt genes ranged in length from 1,744,794-9,333,084 nt.
Only Wnt9 and WntA were found on the same scaffold, but these genes were 829,930 nt apart on this scaffold.

\section{Identification of conserved components of canonical Wnt signaling in Tardigrada}

We were surprised that tardigrades were missing so many Wnt orthologs. This led us to wonder whether these losses were associated with modifications to the cWnt signaling pathway, a highly conserved pathway that utilizes Wnt ligands $[1,4,11,16]$. First, we identified orthologs of wntless, which codes for a transmembrane transport protein that is necessary for secretion of Wnt ligands, in both species of tardigrades (Table 1). Next, we investigated the complement of Frizzled (Fz) genes, which code for receptors of Wnt ligands $[86,87]$.

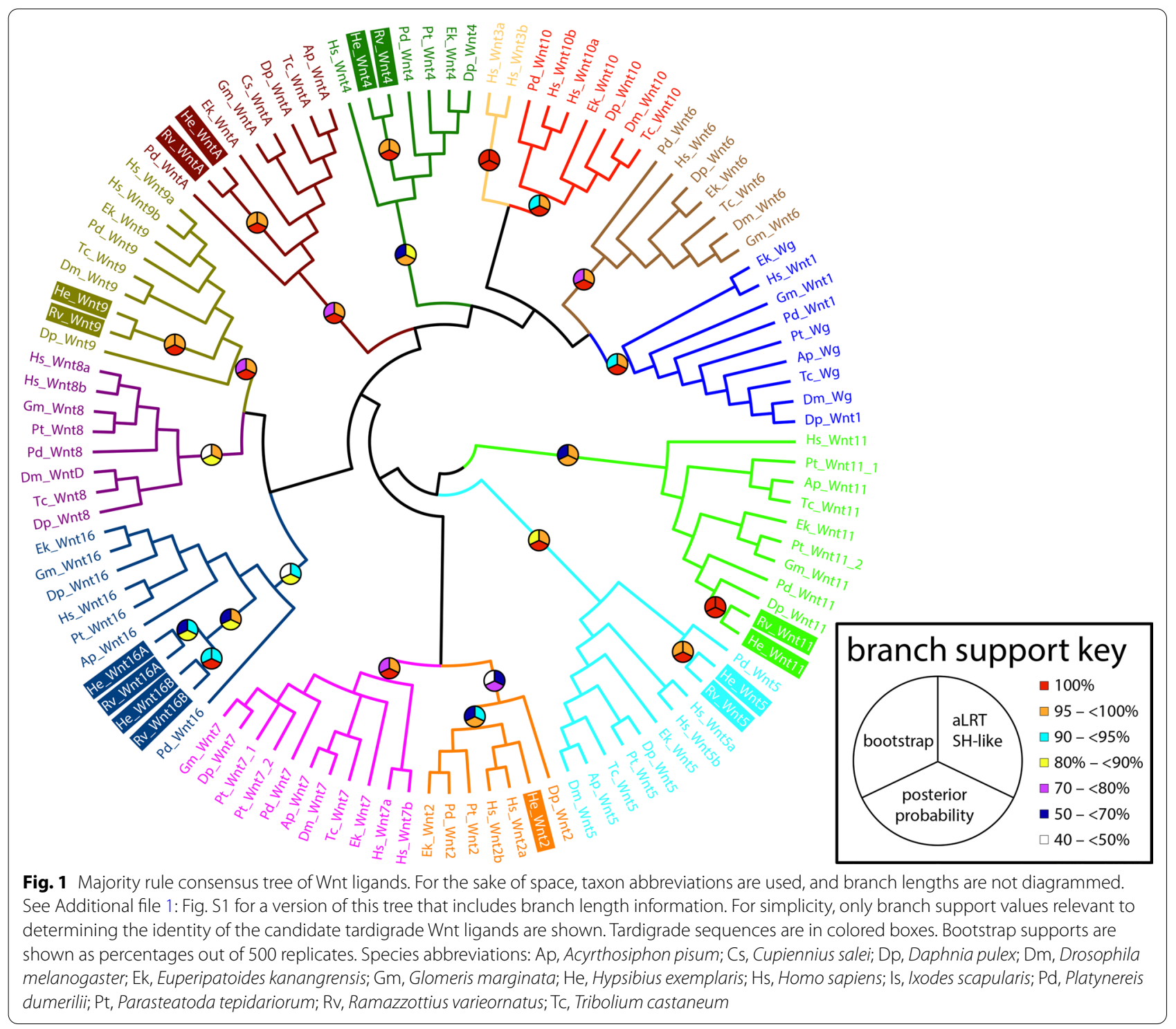


Table 1 Canonical Wnt signaling components in tardigrades. GenBank accession numbers and scaffold numbers are from previously published genome studies [71, 85]. An ortholog of Arrow was not found

\begin{tabular}{|c|c|c|c|c|c|}
\hline \multirow[t]{2}{*}{ Function } & \multirow[t]{2}{*}{ Ortholog } & \multicolumn{2}{|c|}{ Protein accession numbers } & \multicolumn{2}{|c|}{ Scaffold numbers } \\
\hline & & H. exemplaris & R. varieornatus & H. exemplaris & R. varieornatus \\
\hline \multirow[t]{8}{*}{ Ligand } & Wnt2 & OWA52741.1 & - & scaffold0284 & - \\
\hline & Wnt4 & OQV20568.1 & GAV00263.1 & scaffold0029 & BDGG01000006 \\
\hline & Wnt5 & OQV25062.1 & GAU92975.1 & scaffold0004 & BDGG01000002 \\
\hline & Wnt9 & OQV11710.1 & GAU97803.1 & scaffold0163 & BDGG01000004 \\
\hline & Wnt11 & OQV21261.1 & GAU87525.1 & scaffold0024 & BDGG01000001 \\
\hline & Wnt16A & OQV19782.1 & GAU94914.1 & scaffold0035 & BDGG01000003 \\
\hline & Wnt16B & OQV22138.1 & GAV05665.1 & scaffold0019 & BDGG01000012 \\
\hline & WntA & OQV17790.1 & GAU98124.1 & scaffold0056 & BDGG01000004 \\
\hline Transmembrane transport & Wntless & OQV19301.1 & GAV08953.1 & scaffold0041 & BDGG01000019 \\
\hline \multirow[t]{5}{*}{ Receptor } & Fz1 & OQV23182.1 & GAU93634.1 & scaffold0013 & BDGG01000002 \\
\hline & $\mathrm{Fz2}$ & OQV23168.1 & GAU93659.1 & scaffold0013 & BDGG01000002 \\
\hline & Fz3 & OQV21307.1 & GAU87444.1 & scaffold0024 & BDGG01000001 \\
\hline & Fz4 & OQV18791.1 & GAV00601.1 & scaffold0046 & BDGG01000006 \\
\hline & Arrow & - & - & - & - \\
\hline \multirow[t]{2}{*}{ Signal transduction } & Dishevelled & OQV23134.1 & GAV07421.1 & scaffold0013 & BDGG01000015 \\
\hline & Armadillo & OWA50075.1 & GAV07811.1 & scaffold0181 & BDGG01000016 \\
\hline Transcription factor & Pangolin & OQV17172.1 & GAV07782.1 & scaffold0065 & BDGG01000016 \\
\hline \multirow[t]{3}{*}{ cWnt inhibition } & Shaggy & OQV18828.1 & GAU89015.1 & scaffold0045 & BDGG01000001 \\
\hline & APC & OQV22882.1 & GAV03262.1 & scaffold0015 & BDGG01000009 \\
\hline & Axin & OQV22259.1 & GAV03998.1 & scaffold0018 & BDGG01000010 \\
\hline
\end{tabular}

We identified four candidate Fz genes in the genomes of both $H$. exemplaris and R. varieornatus. By CD-search [83], we confirmed that all candidate $\mathrm{Fz}$ genes encoded both a cysteine rich domain and a seven-transmembrane $G$ protein-coupled receptor domain, domains that are indicative of $\mathrm{Fz}$ proteins. A phylogenetic analysis revealed that these candidates are orthologous to the four Fz genes that are found in other panarthropods (Fig. 2; Table 1). We also identified orthologs of genes that encode all major internal components of the cWnt signaling pathway [11], including disheveled, the $\beta$-catenin gene armadillo (arm), three $\beta$-catenin destruction complex genes-axin, shaggy, and Adenomatous polyposis coli tumor suppressor-and pangolin, which codes for a transcription factor that regulates the expression of targets of cWnt signaling (Table 1). However, we were unable to identify an ortholog of arrow, called Lrp5/6 in many animals (Additional file 2: S1). This gene encodes a co-receptor of Wnt ligands, which forms a receptor complex with Fz receptors [88-90]. From N-terminus to C-terminus, arrow orthologs typically encode three clusters of low-density lipoprotein receptor repeat class B domains separated by calciumbinding EGF-like domains, followed by three low-density lipoprotein receptor class A domains (Fig. 3a, b).
This structure was not encoded by the best tardigrade arrow hits (Fig. 3c).

\section{Analysis of Lrp sequences in other bilaterians that exhibit extensive loss of Wnt orthologs}

To better understand the relationship between missing Wnt ligand coding genes and the absence of a clear arrow ortholog in tardigrades, we searched for arrow in the genomes of five additional non-parasitic bilaterian animals that, like tardigrades, are highly miniaturized or evolved from miniaturized ancestors [73, 74, 91, 92], and are missing several Wnt ligand-coding genes $[5,93]$. We focused on free-living miniaturized animals because they may have evolved under similar selective regimes and evolutionary constraints as tardigrades. These animals included the roundworm Caenorhabditis elegans, the rotifer Adineta vaga [94], the flatworm Schmidtea mediterranea [95], the acoel Hofstenia miamia [96], and the meiobenthic annelid Dimorphilus gyrociliatus [97]. D. gyrociliatus possessed a clear ortholog of D. melanogaster arrow (Fig. 3c; Additional file 2: S1). S. mediterranea encoded a gene that was a reciprocal best BLAST hit to D. melanogaster Arrow (Additional file 2: S1). This gene had been identified as an ortholog of arrow/Lrp5/6 in a previous study [98]. The best BLAST hits from the 


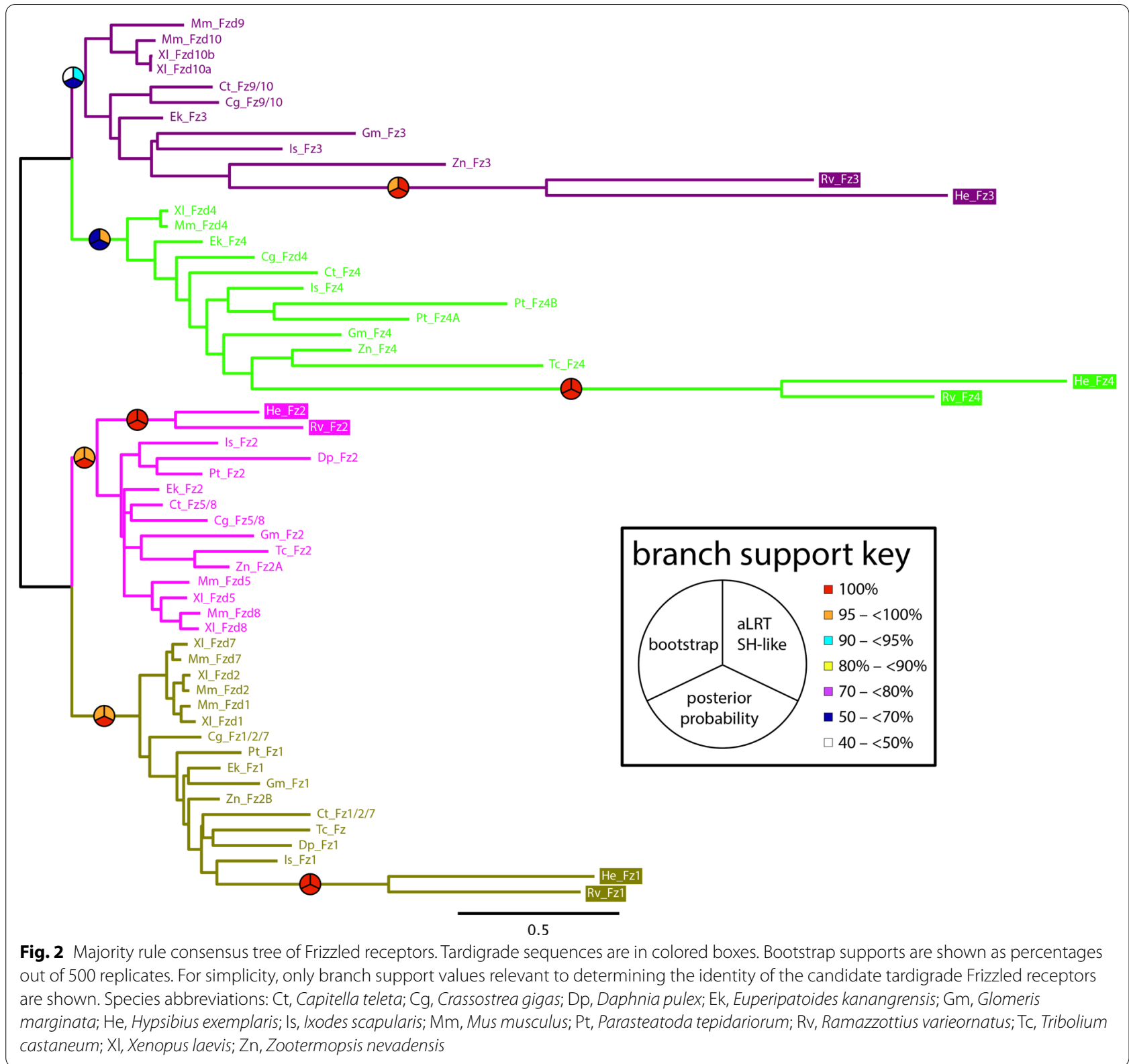

remaining species did not encode the pattern of protein domains that is typical of Arrow (Fig. 3c). A previous study indicated that $C$. elegans has lost an ortholog of arrow/Lrp5/6, in agreement with our results [99]. Next we performed a phylogenetic analysis of Arrow and related sequences. The D. gyrociliatus candidate Arrow/ LRP5/6 ortholog was nested within the clade of Arrow/ LRP5/6 sequences. Of the remaining miniaturized animals that we investigated, only $H$. miamia encoded a sequence that was nested within the clade of Arrow sequences, although this sequence was on a long branch (Fig. 4). Bootstrap support and posterior probability support was low for the Arrow/LRP5/6 clade, likely due to the inclusion of sequences from miniaturized animals, which were generally recovered on long branches. The best matches to $D$. melanogaster Arrow in tardigrade genomes, as determined by BLAST search (Additional file 2: S1), were recovered in a well-supported clade of LRP1 sequences (Fig. 4).

\section{Expression patterns of Wnt genes during tardigrade development}

We analyzed expression of Wnt genes at four different developmental stages in $H$. exemplaris-stage 11, 


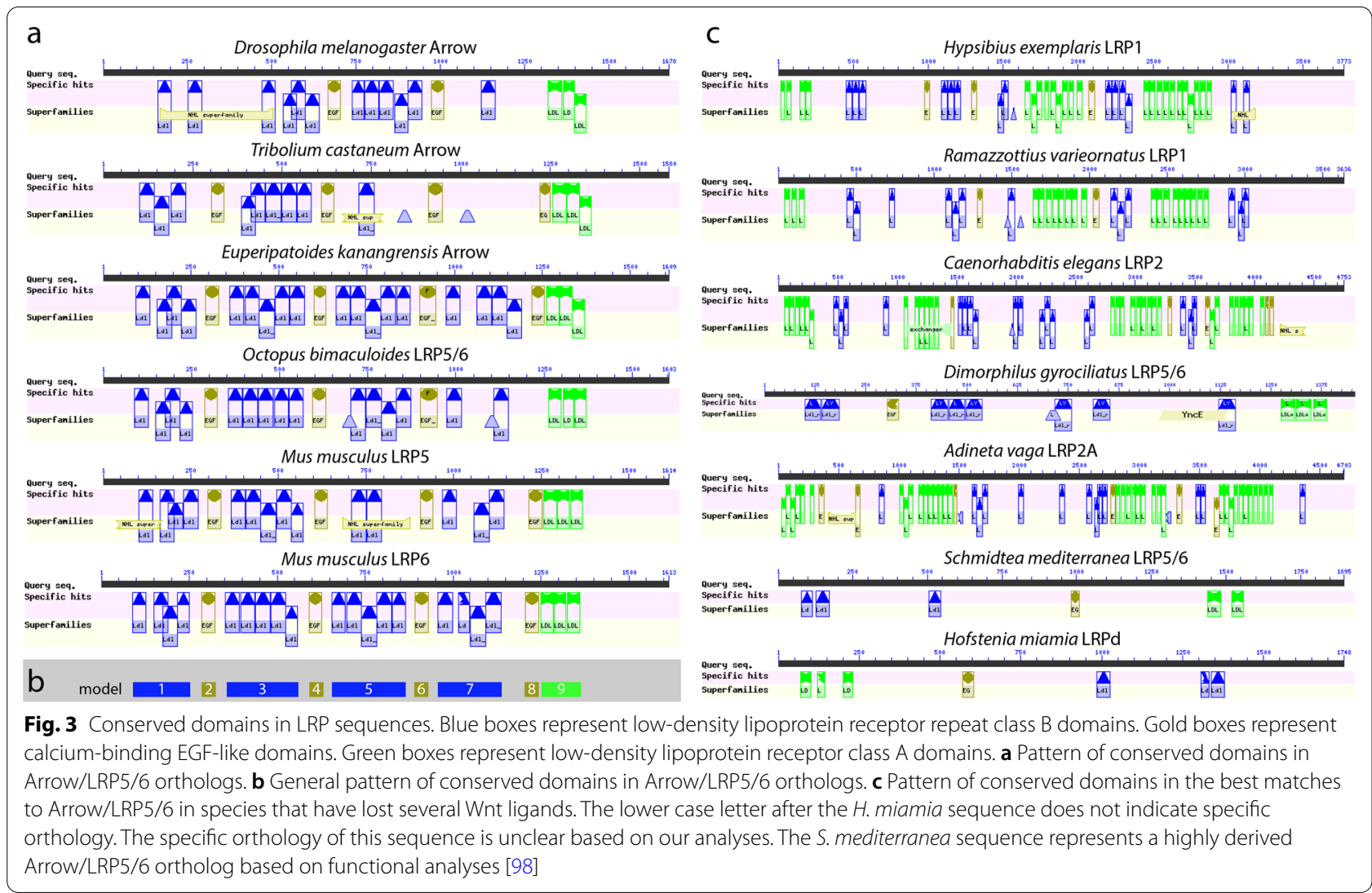

the elongation stage (Fig. 5a, b), stage 12 and 13, when segmental features first appear (Fig. 5c-f), and stage 14, the leg bud stage (Fig. 5g, h) [100]. He-Wnt9 was broadly expressed across embryos at all embryonic stages that we investigated, but may exhibit strongest expression in the endomesodermal layer (Additional file 3: Fig. $\mathrm{S} 2 \mathrm{e}-\mathrm{h}$ ). We did not detect clear $\mathrm{He}-\mathrm{Wnt} 16 \mathrm{~A}$ expression at any stage that we investigated (Additional file 3: Fig. $\mathrm{S} 2 \mathrm{~m}-\mathrm{p}$ ). The AP axis forms by a process referred to as elongation during stage 11 in $H$. exemplaris-a process during which the entire AP axis forms simultaneously, rather than forming in anteroposterior order as would be indicative of posterior growth (Fig. 5a, b) [100]. We analyzed He-six3 expression, a marker of anterior identity $[76,101]$, with in situ hybridization at stage 11 to distinguish between the anterior and posterior embryonic poles (Fig. 6a, b). In stage 11 embryos, an internalized cell layer extended to the external ectodermal cell layer at one embryonic pole (Fig. 5a, b). Six3 was expressed at the opposite pole (Fig. 6a', b'), indicating that the internalized cells connect to the ectoderm at the posterior side of stage 11 embryos. At stage 11, He-Wnt2, He-Wnt4, and $H e-W n t 16 B$ were expressed in the ectodermal layer near the posterior embryonic pole (Fig. 6c, c', d, d', i, i'). $H e$-Wnt11 appeared broadly expressed at this stage, but the strongest signal was located near the presumptive posterior end of the embryo (Fig. 6h-h"'; Additional file 3: Fig. S2i). The expression domains of $\mathrm{He}-\mathrm{Wnt} 5$ and $\mathrm{He}-\mathrm{WntA}$ were localized to the ectodermal layer, between the anterior and posterior poles of embryos (Fig. 6e-g, j, j'). He-Wnt5 expression extended across the presumptive dorsoventral axis, whereas $H e-W n t A$ expression was restricted to the presumptive ventrolateral region of embryos. The $\mathrm{He}$-Wnt5 expression domain shifted to a slightly more anterior location in late stage 11 embryos (Fig. 6g, g'), which may be associated with movement of cells during the elongation process.

After elongation, the AP axis is curved in a characteristic " $C$ " shape. At stage 12, the developing foregut in the head and trunk endomesoderm is visible (Fig. 5c, d) [100]. We did not detect strong signal for $\mathrm{He}-\mathrm{Wnt} 2$ at this stage or later stages (Additional file 3: Fig. S2a-c). HeWnt4 was expressed in the endomesodermal layer of the developing trunk (Fig. 7b, b'). He-Wnt5 was expressed in the ventrolateral ectoderm of the posterior head (Fig. 7c, d). He-Wnt11 signal was detected broadly across embryos at stage 12 , but the strongest expression was localized to the posteriormost region of developing embryos (Fig. 7e, e'; Additional file 3: Fig. S2j). He-Wnt16B was expressed broadly across the posterior half of the developing trunk, 


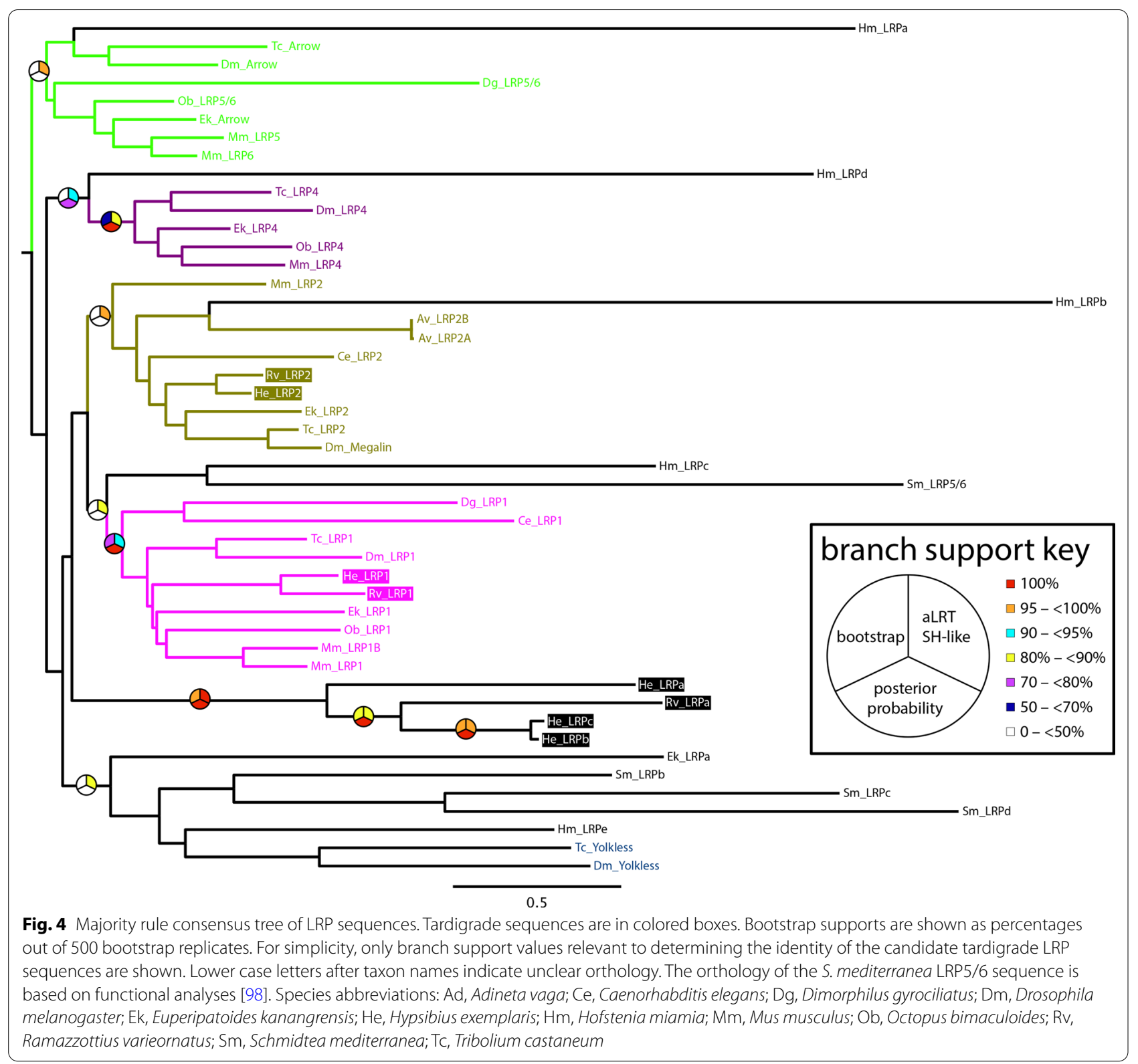

(See figure on next page.)

Fig. 5 Elongation, segmentation, and leg development stages in H. exemplaris. Panels to the left show DAPI stained embryos. Models are provided to the right of each data panel. The key for the color-coding in models is provided at the bottom of the figure. a Early elongation (stage 11). $\mathbf{b}$ Late elongation (stage 11). a, b Arrowhead points to internalized cells that connect to the external ectoderm. $\mathbf{c}$, d Stage 12. e, f Stage 13. e-e" Views from more lateral to more medial. $\mathbf{e}, \mathbf{f}$ Dashed lines in the model denote the position of ectodermal furrows. $\mathbf{g}, \mathbf{h}$ Stage 14 . Anterior is towards the top in all panels. All panels show a lateral view of embryos facing right except for $\mathbf{d}$, $\mathbf{f}$, and $\mathbf{h}$, which show bilateral views. All panels show internal anatomy, except for $\mathbf{e}$ and $\mathbf{g}$, which show external features. ant anterior; ep 1-ep4 endomesodermal pouch 1-endomesodermal pouch 4; fg foregut; 11-14 leg 1-leg 4; pos posterior, t1-t4 trunk segment 1-trunk segment 4

excluding the posteriormost region (Fig. 7f, f'). He-WntA was expressed in the ectodermal layer in the anteriormost region of the developing trunk and posteriormost part of the head (Fig. $7 \mathrm{~g}-\mathrm{h}$ ).
At stage 13, segmentation is clearly visible in the form of ectodermal furrows and endomesodermal pouches (Fig. 5e, f) [100]. He-Wnt4 was expressed strongest in the endomesodermal layer of the developing trunk (Fig. 8a, 

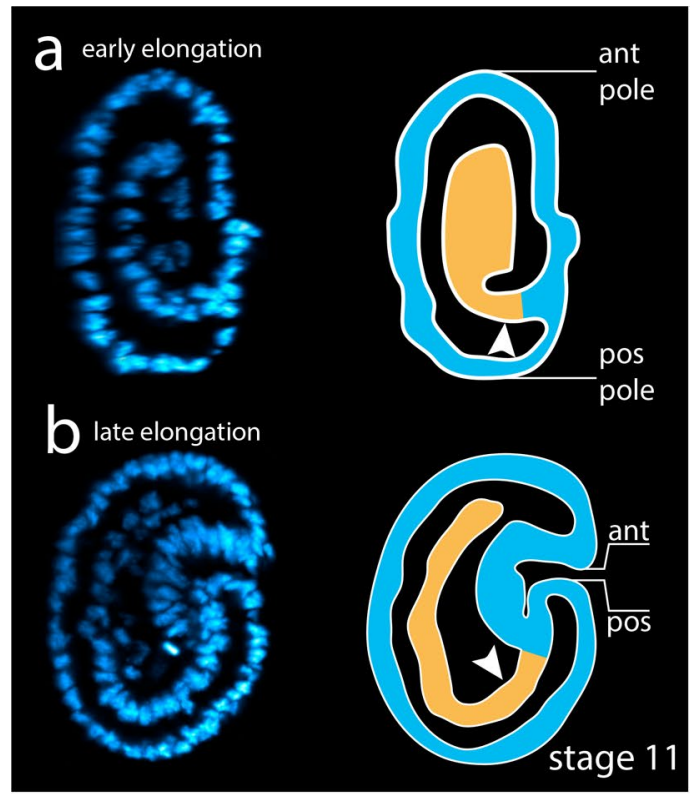

pole
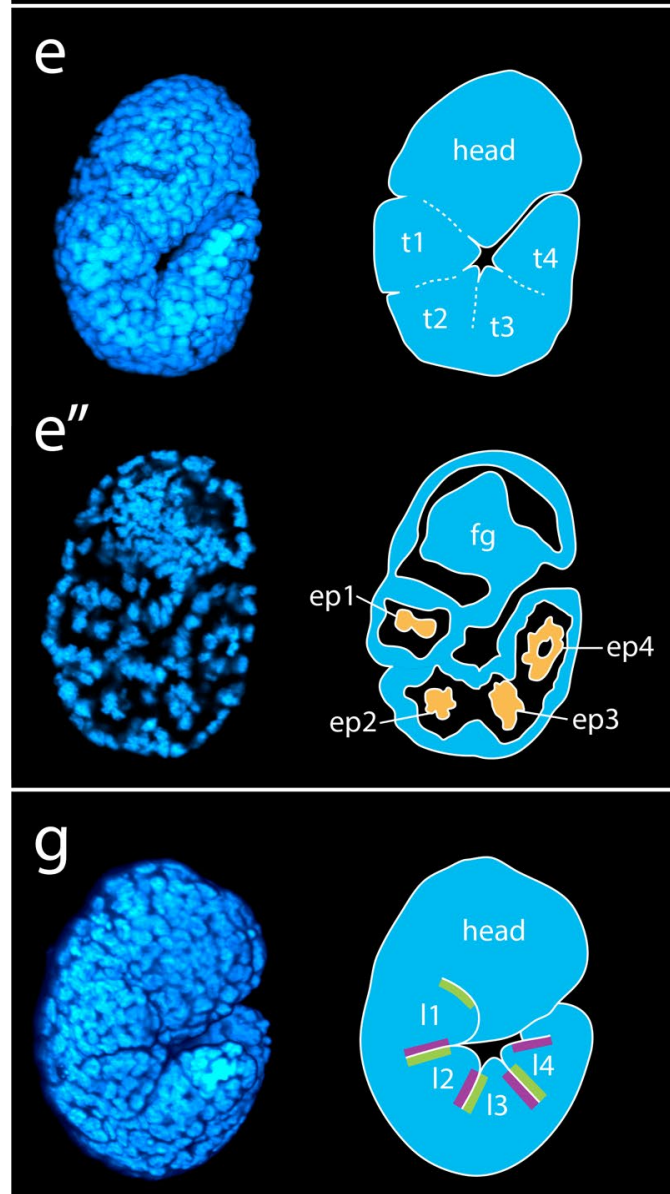
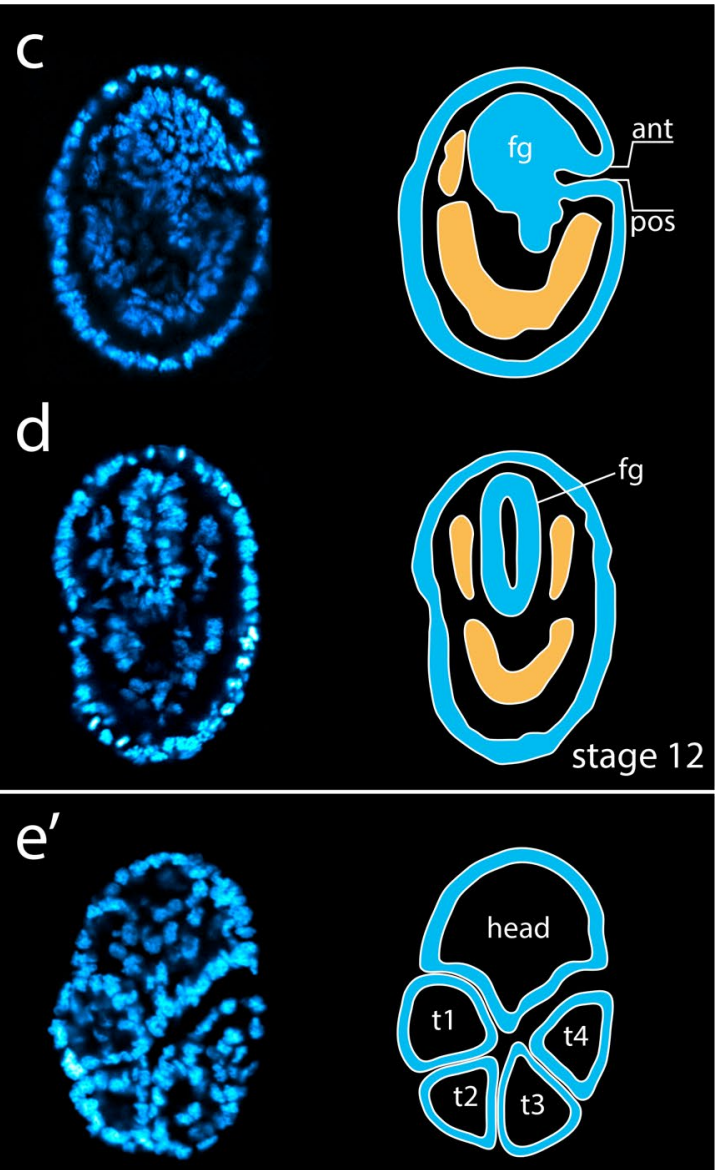

f
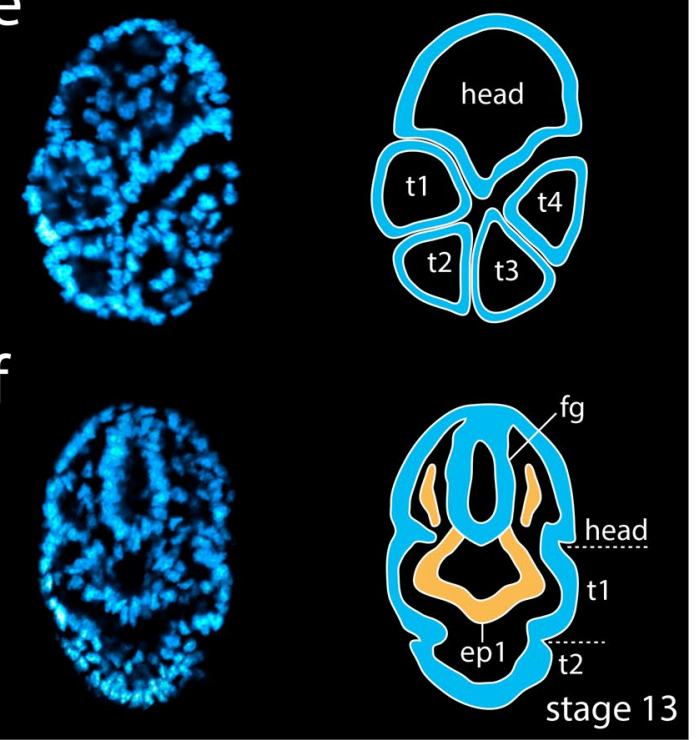

h

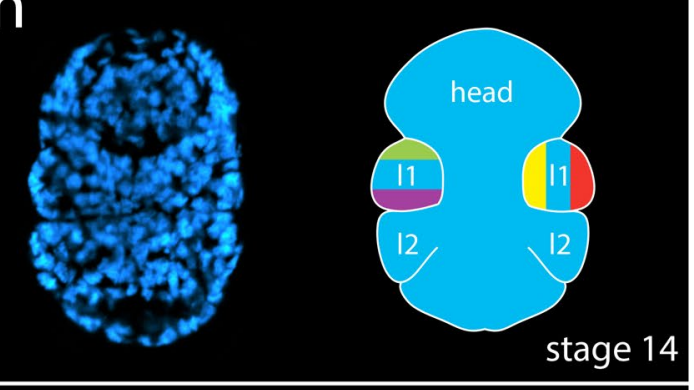

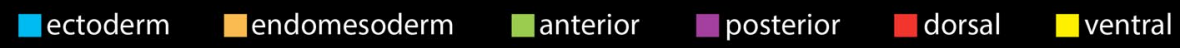

Fig. 5 (See legend on previous page.) 
b). At stage 13, He-Wnt5 expression looked very similar to its expression at stage 12 . At this stage, $\mathrm{He}-\mathrm{Wnt5}$ was primarily expressed in a ventrolateral region of the ectodermal layer of the developing head (Fig. 8c, d). $\mathrm{He}$ Wnt 11 was expressed broadly across developing embryos (Additional file 3: Fig. S2k). He-Wnt16B was expressed in the lateral ectoderm of the third and fourth trunk segment, excluding the posteriormost region of the fourth trunk segment (Fig. 8e, f). He-WntA was expressed in a dorsolateral stripe in the boundary between the head and the first trunk segment (Fig. 8g, g').

At stage 14, developing legs are clearly visible (Fig. 5g, h). Other features, such as pharynx and trunk ganglia are also visible [100]. At this stage, $\mathrm{He}-\mathrm{Wnt} 4$ was very weak or absent (Additional file 3: Fig. S2d). $\mathrm{He}-\mathrm{Wnt} 5$ was expressed broadly across the inner surface of developing legs, between the developing hind legs, in the ventrolateral ectoderm of the head, and in the developing pharynx (Fig. 9a-b"). He-Wnt11 exhibited strongest expression in the posteriormost region of the AP axis, between the developing hind legs, at this stage (Fig. 9c, d). We also detected staining for $\mathrm{He}$-Wnt11 in other parts of the embryo (Additional file 3: Fig. S2l). At stage 14, $\mathrm{He}-\mathrm{WntA}$ was expressed in a dorsolateral ectodermal stripe between the head and first trunk segment, and in the developing pharynx (Fig. 9g, g'). He-Wnt16B was expressed in a stripe in each developing leg (Fig. 9e, f', f"). We also detected expression of this gene in the posteriormost region between the developing hind legs (Fig. 9e, f"), and near the posterior part of the pharynx, which likely represents the esophagus (Fig. 9f).

\section{Discussion}

\section{Evolutionary dynamics of Wnt genes in Tardigrada}

Orthologs of Wnt2, Wnt4, Wnt5, Wnt9, Wnt11, Wnt16, and $W n t A$ are conserved in Tardigrada (Fig. 1). By contrast, Wnt1, Wnt6, Wnt7, Wnt8, and Wnt10 are missing in the genomes of two tardigrade species, $H$. exemplaris and $R$. varieornatus. These genes were most likely lost specifically within the tardigrade lineage (Fig. 10). However, these two tardigrade species are fairly closely related [78]. Therefore, whether these genes were lost in an ancestor of all tardigrades, or within crown group Tardigrada is unclear. Likewise, it is difficult to place the duplication event that gave rise to Wnt16 paralogs. It is clear that this duplication event occurred somewhere in the tardigrade lineage, because tardigrade Wnt16 genes formed a well-supported monophyletic group in our phylogenetic analyses (Fig. 1). It is also clear that these genes evolved by a duplication event that occurred in an ancestor of both $H$. exemplaris and $R$. varieornatus, rather than by independent duplication events (Fig. 10). The fact that the closest relative of $H e-W n t 16 A$ is $R v-W n t 16 A$ and the closest relative of $H e-W n t 16 B$ is $R v-W n t 16 B$ supports this conclusion (Fig. 1). As with the losses of Wnt genes, this duplication event could have occurred in any common ancestor of $H$. exemplaris and $R$. varieornatus in the tardigrade lineage. Genomic data from more distantly related tardigrade species would enable a more precise phylogenetic resolution of tardigrade specific losses and duplication of Wnt genes. By contrast, we can more precisely resolve the absence of $W n t 2$ in the genome of $R$. varieornatus as a loss in the lineage leading to this species after it split from the lineage leading to $H$. exemplaris, because $W n t 2$ is retained in $H$. exemplaris and outgroups of Tardigrada (Fig. 10).

Additionally, our results suggest that Wnt genes are dispersed throughout a chromosome or several chromosomes in the tardigrade species that we investigated, rather than clustered like Wnt genes in some other animal genomes $[2,5,59]$. The dispersion of Wnt genes in the genome most likely represents a derived state and could be related to the extensive loss of Wnt genes. Dispersion of ancestrally clustered paralogs in tardigrade genomes has been previously suggested for Hox genes and NK homeobox genes $[75,102]$. Therefore, dispersion of ancestrally clustered paralogs of developmental genes could represent a general pattern of genome evolution in the tardigrade lineage. The evolution of rapid embryogenesis has been suggested to abrogate purifying selection that would otherwise maintain clustered Hox genes and Parahox genes [103], and may also explain the dispersion of Wnt genes and NK homeobox genes in tardigrade genomes. Additionally, dispersion of ancestrally clustered paralogous developmental genes has been suggested to represent a general outcome of miniaturization [74].

In contrast to the extensive loss of Wnt orthologs, we identified nearly all other components of the cWnt signaling pathway in tardigrades (Table 1). This was not surprising given that $\mathrm{cWnt}$ signaling regulates many developmental processes in other animals. However, we

(See figure on next page.)

Fig. 6 In situ hybridization results for Wnt genes in stage 11 H. exemplaris embryos. Green color represents gene expression. Nuclei are labeled with DAPI (blue). Images that share the same letter represent data from the same embryo. Arrowheads point to internal cells that connect to the ectoderm at the posterior end. Anterior is towards the top. a Six3 expression in early elongation stage embryos. b Six 3 expression in late elongation stage embryos. c Wnt2 expression. $\mathbf{d}$ Wnt 4 expression. e, $\mathbf{f}$ Wnt5 expression in early elongation stage embryos. $\mathbf{g}$ Wnt5 expression in late elongation stage embryos. $\mathbf{h}$ Wnt1 1 expression. $\mathbf{i}$ Wnt16B expression. $\mathbf{j}$ WntA expression. $\mathbf{f}, \mathbf{g}^{\prime}, \mathbf{h}^{\mathbf{\prime}}$, $\mathbf{j}^{\prime}$ Bilateral view showing internal anatomy. $\mathbf{h}^{\prime \prime}$ Bilateral view of outer ectoderm. All other panels show lateral views of embryos that are facing right. $\mathbf{a}^{\prime}-\mathbf{d}^{\prime}, \mathbf{h}^{\prime}, \mathbf{i}^{\prime}$ show internal anatomy of laterally viewed embryos 


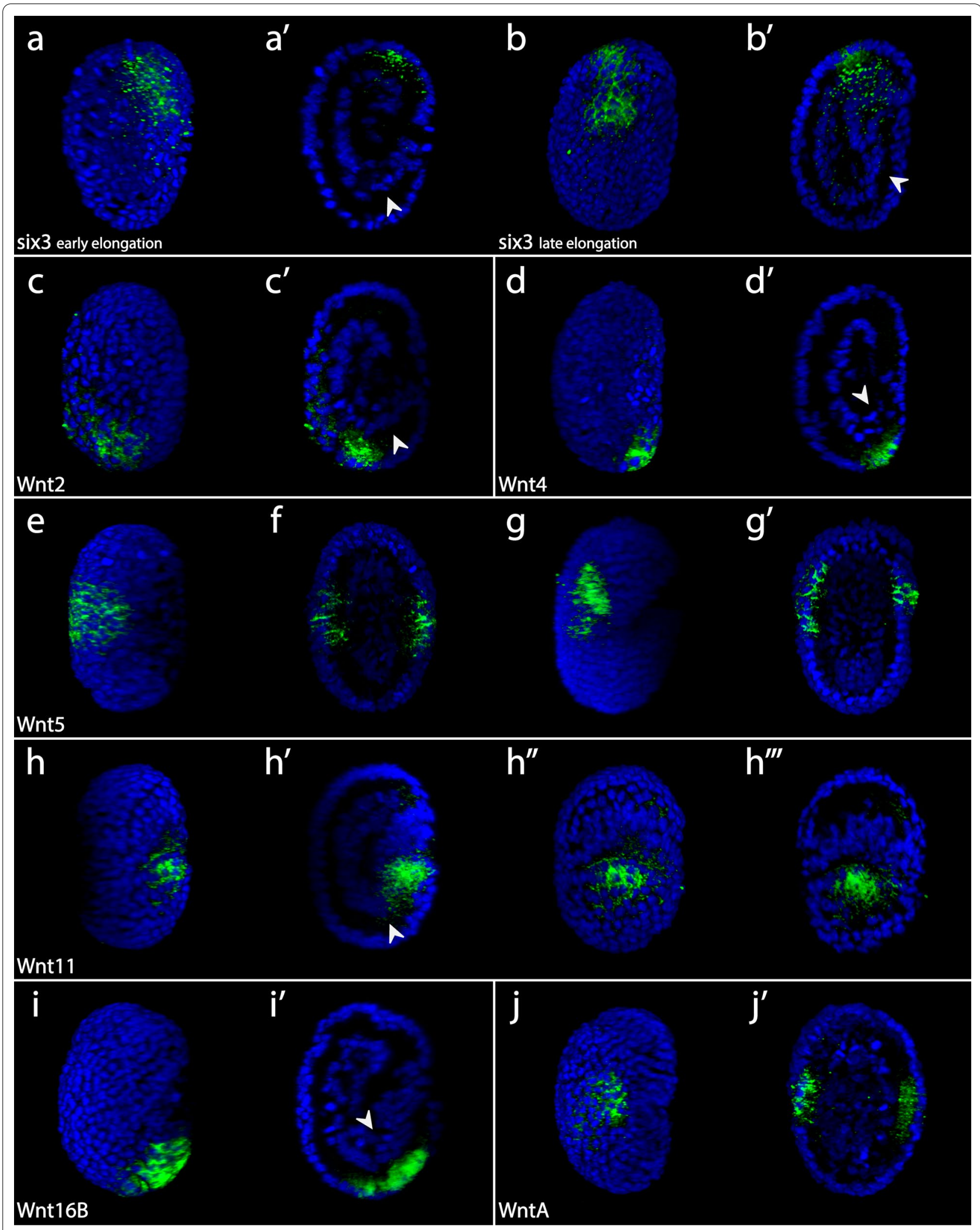

Fig. 6 (See legend on previous page.) 


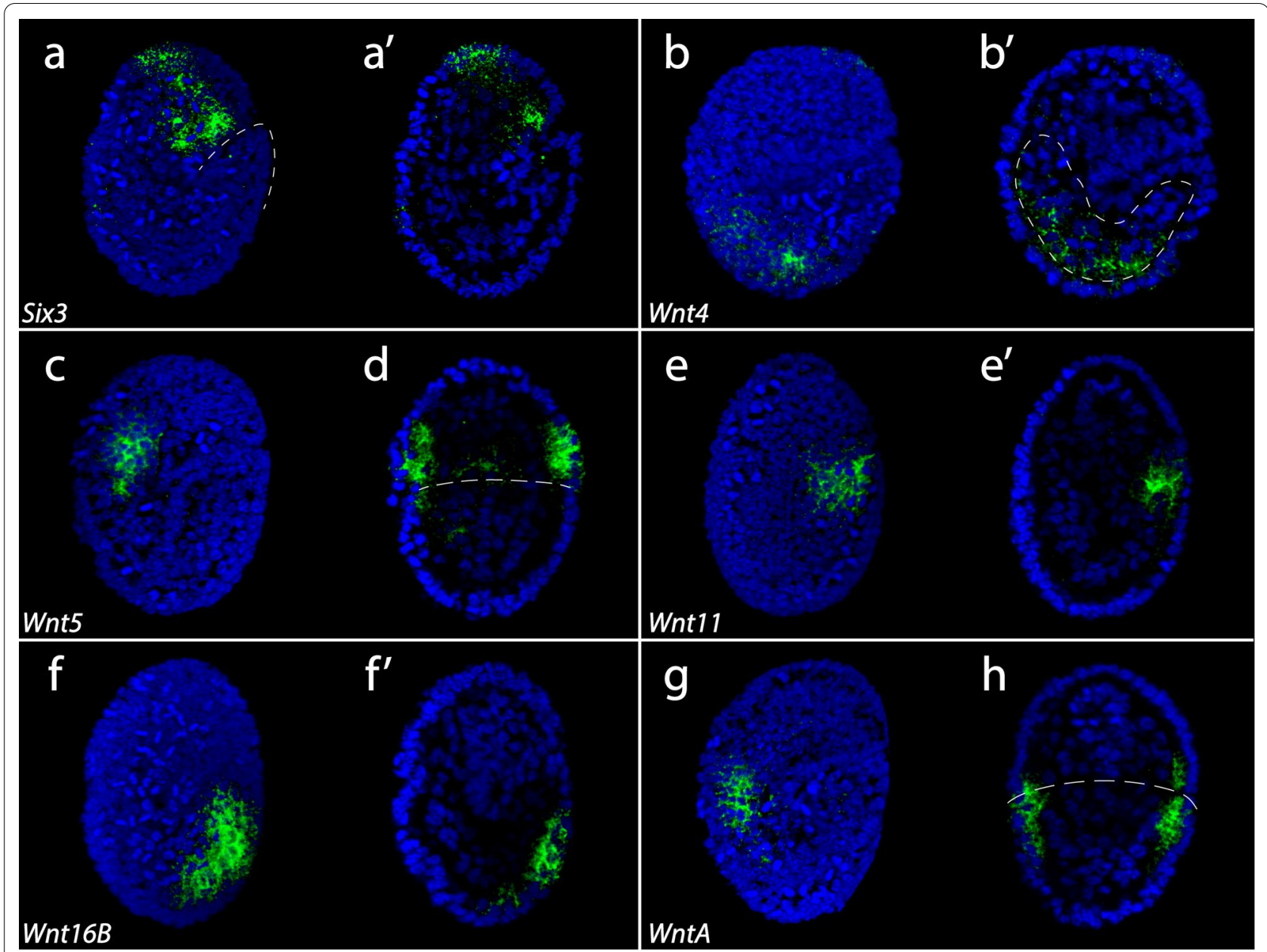

Fig. 7 In situ hybridization results for Wnt genes in stage 12 H. exemplaris embryos. Green color represents gene expression. Nuclei are labeled with DAPI (blue). Images that share the same letter represent data from the same embryo. Anterior is towards the top. a Six3 expression. Dashed line outlines the posterior tip. $\mathbf{b}$ Wnt4 expression. c, $\mathbf{d}$ Wnt5 expression. e Wnt11 expression. $\mathbf{f}$ Wnt $16 B$ expression. $\mathbf{g}, \mathbf{h}$ WntA expression. All panels show lateral views of embryos that are facing right except for $\mathbf{d}$ and $\mathbf{h}$ which are bilateral views showing internal anatomy. $\mathbf{a}^{\prime}, \mathbf{b}^{\prime}, \mathbf{e}^{\prime}, \mathbf{f}^{\prime}$ show internal anatomy of laterally viewed embryos. $\mathbf{b}^{\prime}$ Dashed lines outline developing endomesodermal pouches. $\mathbf{d}, \mathbf{h}$ Dashed line demarcates the boundary between the head and the trunk

were unable to identify an ortholog of arrow (Additional file 2: S1), referred to as Lrp5/6 in many animals, which codes for a co-receptor of Wnt ligands [88-90, 104]. The closest match to arrow in tardigrades is a gene that most likely codes for an Lrp1 ortholog (Figs. 3c, 4). Possibly, the Wnt ligands that were lost in Tardigrada represent the Wnt ligands that required Arrow as a co-receptor to activate cWnt signaling in the ancient ancestors of tardigrades. To test this hypothesis, more studies are required to determine exactly which Wnt ligands require Arrow for cWnt signaling broadly across Metazoa.

\section{Potential correlates of Wnt gene loss in Tardigrada}

Barring initial redundancy, which is a poor explanation for long-term retention of Wnt paralogs [3], the loss of
Wnt genes in the tardigrade lineage is most likely associated with modifications to development in Tardigrada. However, identifying exactly how development has been modified in tardigrades is extremely difficult, especially given the relatively scarce functional data for most Wnt genes. Additionally, we should not draw strong conclusions based on the loss of several Wnt genes in Tardigrada, given that gene loss is very common in this lineage $[97,105]$, and given that the loss of one or more Wnt gene(s) is fairly common across Metazoa [3]. Nonetheless, a comparative approach may help explain the extensive loss of Wnt genes in Tardigrada. First, we note that, in addition to tardigrades, several other secondarily miniaturized animals exhibit extensive loss of Wnt genes (Fig. 10, Caenorhabditis, Adineta, Schmidtea, 


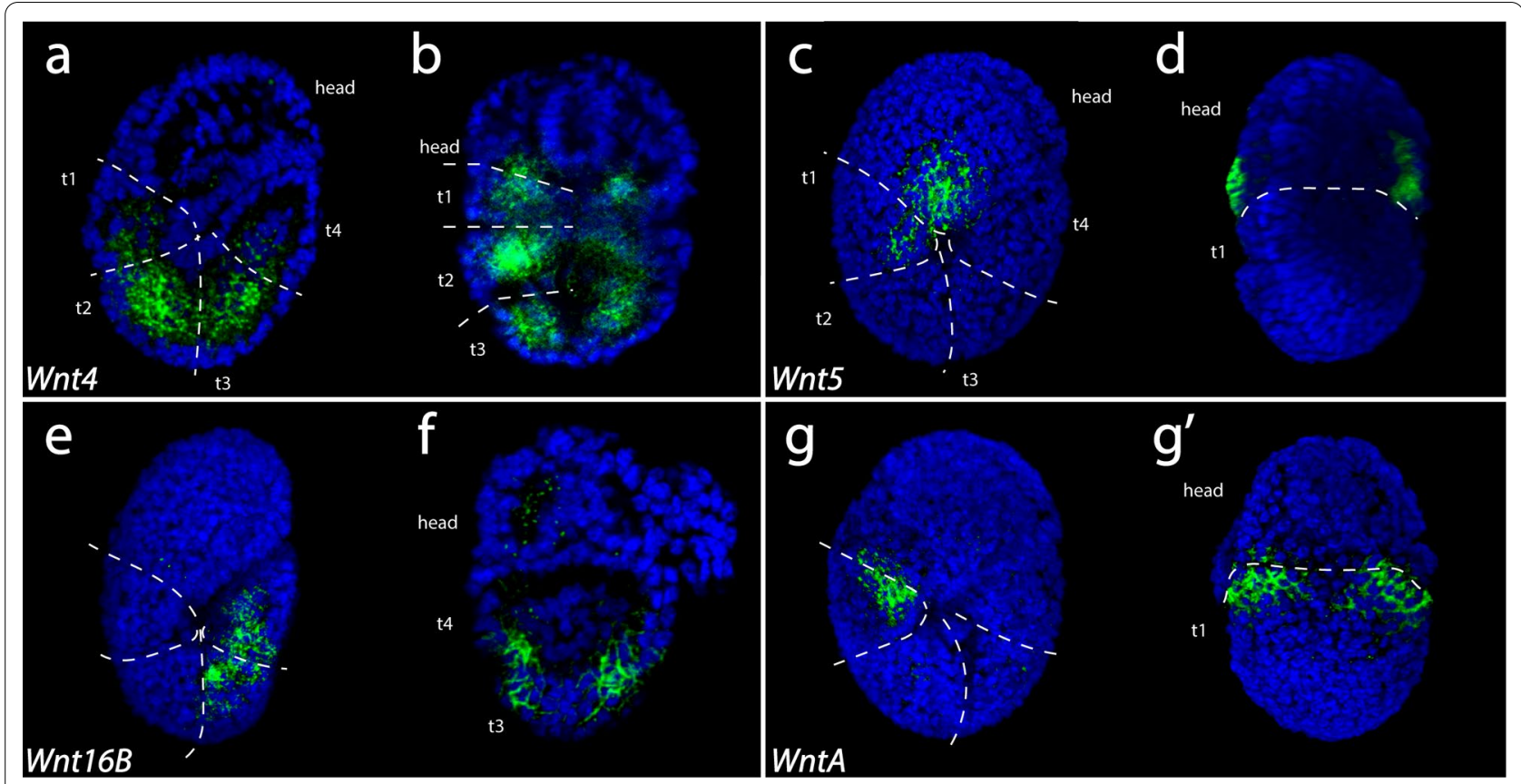

Fig. 8 In situ hybridization results for Wnt genes in stage 13 H. exemplaris embryos. Green color represents gene expression. Nuclei are labeled with DAPI (blue). Images that share the same letter represent data from the same embryo. Anterior is towards the top. $\mathbf{a}, \mathbf{b}$ Wnt4 expression. $\mathbf{c}, \mathbf{d}$ Wnt5 expression. e, f Wnt $16 B$ expression. g, $\mathbf{g}^{\prime}$ WntA expression. $\mathbf{a}, \mathbf{c}, \mathbf{e}, \mathbf{g}$ Lateral view of embryos that are facing right. $\mathbf{d}$, $\mathbf{g}^{\prime}$ Bilateral views showing external anatomy. f Bilateral view showing internal anatomy. Dashed line demarcates the boundary between the head and the trunk. $\mathbf{a}, \mathbf{b}, \mathbf{c}, \mathbf{e}, \mathbf{g}$ Dashed lines demarcate segment boundaries. t1-t4 trunk segment 1-trunk segment 4

Dimorphilus, Hofstenia) [3, 5, 97, 106, 107]. The extensive loss of Wnt genes in some secondarily miniaturized animals may be due to the evolution of simpler cell fate specification mechanisms related to reduction in cell number and simplified morphology that often accompanies miniaturization. Along these lines, our expression data suggest that combinatorial interactions among Wnt genes may play a much less important role during development of tardigrades compared to typical macroscopic animals. In arthropods, onychophorans, and annelids, several Wnt genes are coexpressed in the posterior growth zone and are expressed in similarly positioned segmentally reiterated stripes [3, 28, 108]. Although Wnt genes exhibit different expression patterns during appendage development between arthropods and onychophorans (see below), within each lineage, several Wnt genes exhibit very similar expression patterns during appendage development [3, 28, 63]. Similar expression patterns of different Wnt genes in arthropods, onychophorans, and annelids most likely reflect combinatorial interactions of these genes during development [3]. Necessary combinatorial interactions of several Wnt paralogs could partly explain their conservation across much of Metazoa. None of the Wnt genes in $H$. exemplaris exhibited highly similar expression patterns during segmentation or leg development. Therefore, combinatorial interactions between Wnt orthologs must be less important during development of tardigrades. In some secondarily miniaturized animals, like tardigrades, one or more Wnt genes may become superfluous or redundant with a reduced requirement of combinatorial interactions, ultimately leading to loss by neutral evolutionary processes.

A second non-mutually exclusive possibility is that the loss of one or more Wnt genes in Tardigrada is related to the loss of posterior growth, a process that is regulated by cWnt signaling in many macroscopic animals [20, $21,27,109,110]$. As with tardigrades, posterior growth is reduced, absent, or highly modified in many secondarily miniaturized animals $([79,100,111,112]$, MartínDurán JM, pers. comm.), which have also lost several Wnt genes (Fig. 10, Caenorhabditis, Adineta, Schmidtea, Dimorphilus, Hofstenia). Additionally, long germband insects may retain fewer ancestral Wnt genes than their short germband relatives that continue to utilize posterior growth (Fig. 10, compare the long germband insects Drosophila, Anopholes, and Apis to the shortband insect Tribolilum) [3]. Arrow/Lrp5/6 is also necessary for normal posterior growth in arthropods and vertebrates [54, 113-115]. Therefore, the loss of arrow/Lrp5/6 in tardigrades and several other miniaturized animals may represent an additional genomic signature of the loss of posterior growth in these animals. 

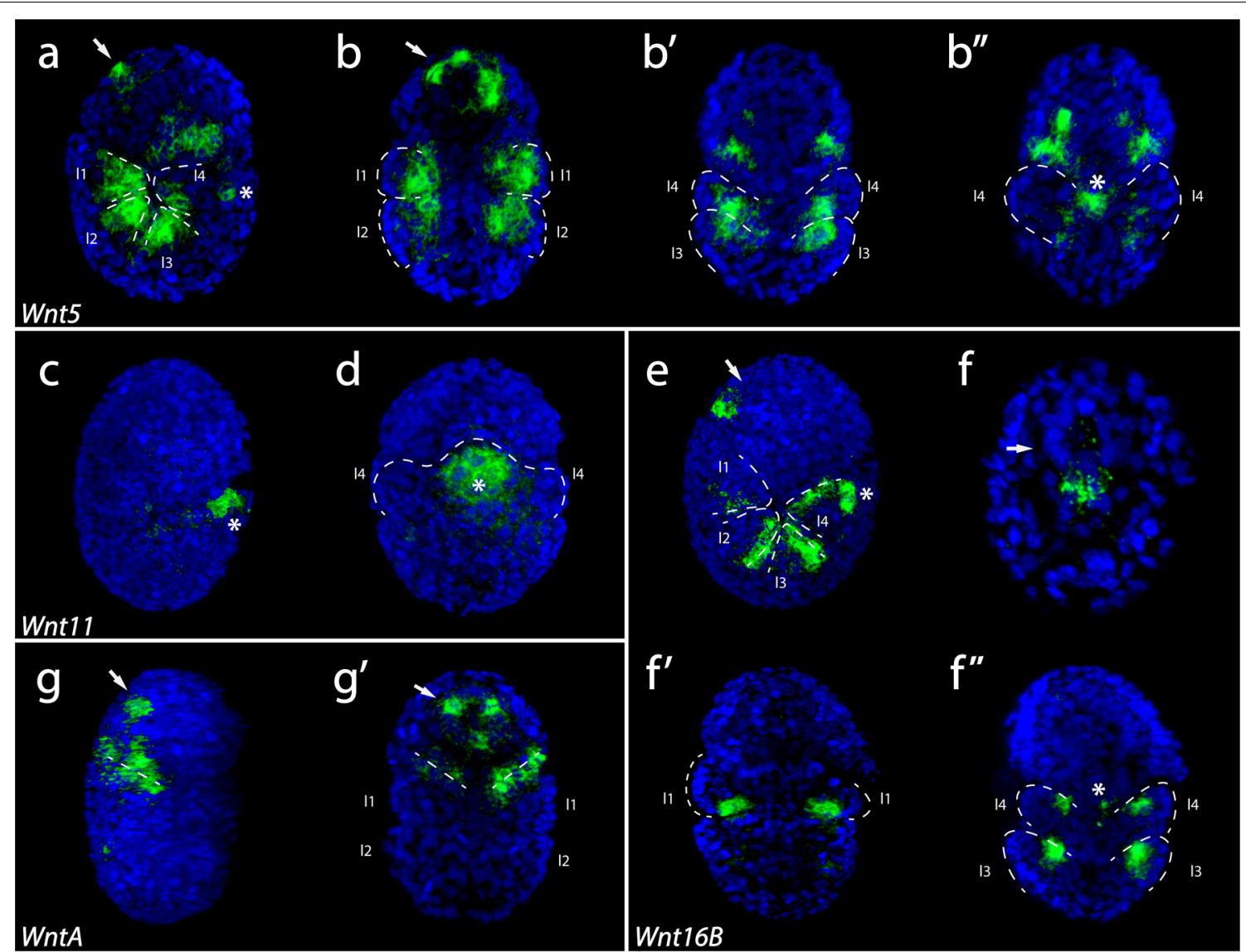

Fig. 9 In situ hybridization results for Wnt genes in stage 14 H. exemplaris embryos. Green color represents gene expression. Nuclei are labeled with DAPI (blue). Images that share the same letter represent data from the same embryo. Arrows point to the developing pharynx. Asterisks mark the region between the posteriormost legs. Anterior is towards the top. $\mathbf{a}, \mathbf{b}$ Wnt5 expression. a Ventral surface of legs is in view. $\mathbf{b}$, $\mathbf{b}^{\prime}$ Dorsal surface of legs is toward the outside and the ventral surface is toward the inside of the embryo. $\mathbf{c}, \mathbf{d}$ Wnt11 expression. $\mathbf{d}$ Bilateral view. The posterior end of embryo is outlined. e, $\mathbf{f}$ Wnt16B expression. $\mathbf{g}$ WntA expression. $\mathbf{a}-\mathbf{b}^{\prime \prime}, \mathbf{e}, \mathbf{f}^{\prime}, \mathbf{f}^{\prime \prime}$ Dashed lines outline legs. $\mathbf{a}, \mathbf{c}, \mathbf{e}, \mathbf{g}$ Lateral view of embryos that are facing right. b-b", $\mathbf{f}-\mathbf{f}^{\prime \prime}, \mathbf{g}^{\prime}$ Bilateral view showing internal anatomy. $\mathbf{g}, \mathbf{g}^{\prime}$ Dashed lines demarcate the boundary between the head and the trunk. 11-14 leg 1-leg 4

Although feasible, there are significant difficulties associating the loss of Wnt genes and arrow/Lrp5/6 with the loss of posterior growth. First, the loss of arrow $/ \mathrm{Lrp} 5 / 6$ is not tightly associated with the loss of Wnts genes or posterior growth. For example, D. gyrociliatus retains an arrow/Lrp5/6 ortholog (Figs. 3c, 4; Additional file 2: S1), but is missing several Wnt genes (Fig. 10, Dimorphilus) [97] and lacks posterior growth (Martín-Durán JM, pers. comm.). Likewise, although long germband insects have lost several Wnt genes and do not utilize posterior growth, they retain arrow [88]. Therefore, arrow clearly plays important developmental roles besides regulating posterior growth. Evidence for an additional role of arrow/Lrp5/6 comes from studies of the flatworm $S$. mediterranea. In this species, this gene is required to regulate posterior cell fate and proliferation during AP axis regeneration [98]. Second, given the sparse data available in regards to which Wnt gene regulates posterior growth, and the apparent interchangeability of Wnt gene function in this process based on data that are available $[26,58]$, it is not possible to associate with confidence the loss of any particular Wnt gene in tardigrades with the loss of posterior growth. Nonetheless, based on a comparative perspective, it remains possible that reduced combinatorial interactions and the loss of posterior growth, both associated with miniaturization, contributed to the loss of several Wnt genes and arrow/Lrp5/6 in Tardigrada.

\section{Wnt genes and regionalized AP cell fate specification}

Several Wnt genes appeared to be expressed in regionalized patterns along the developing AP axis during embryogenesis in $H$. exemplaris. Given the absence of segment markers during elongation, it is difficult to determine precisely where the Wnt genes are expressed during this 


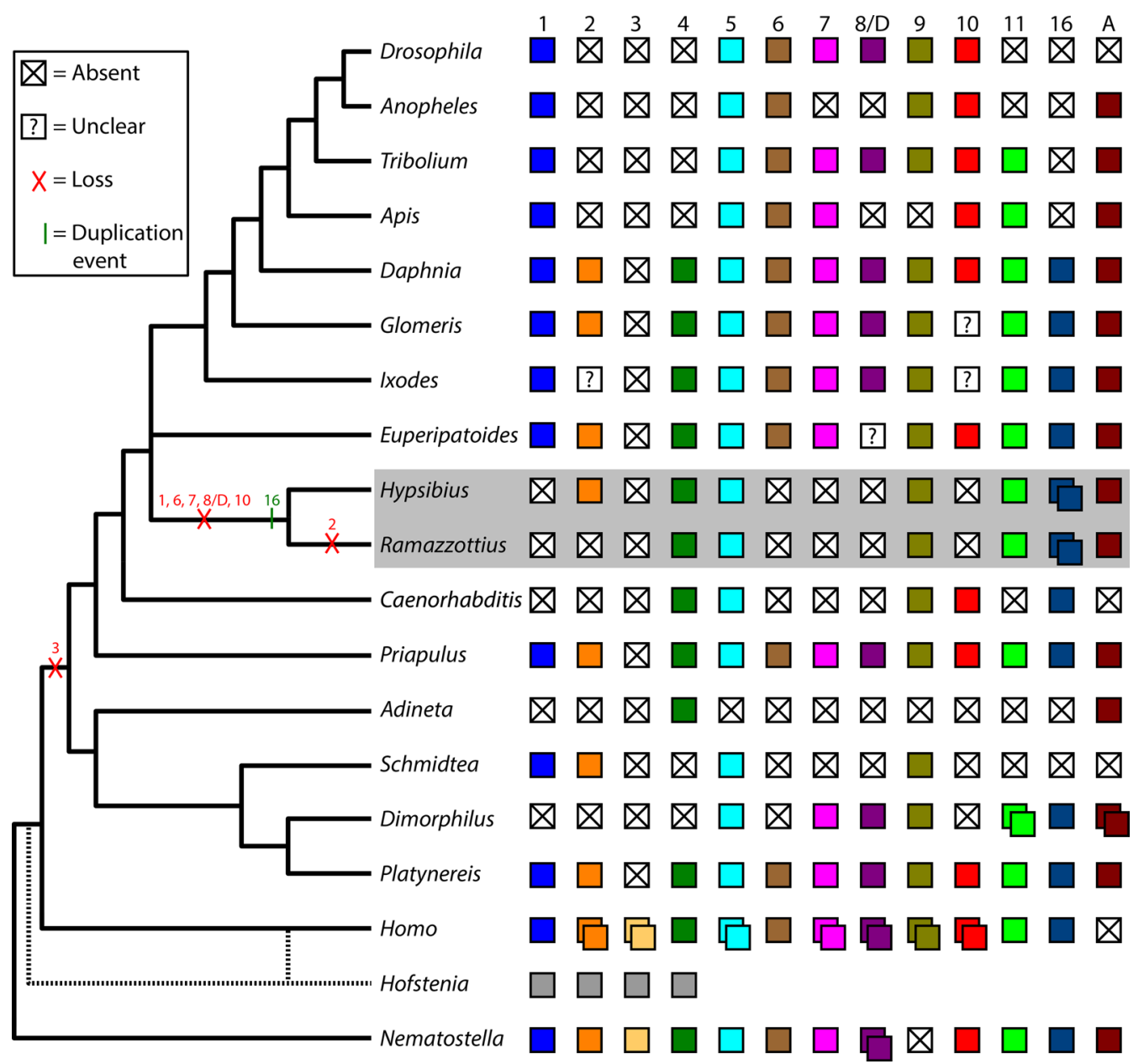

Fig. 10 Summary of distribution of Wnt orthologs in metazoan genomes. " $X$ " in white boxes indicates the loss of a Wnt gene. "?" in white boxes indicates that a fully sequenced genome is unavailable for the associated lineage, so it is unclear whether the ortholog has been lost, or is present, but unsequenced. Gray boxes associated with Hofstenia indicate unclear orthology of the four Wnt genes found in the genomes of representatives of this lineage. Dashed lines coming off of Hofstenia represent different hypotheses of the relationship of this lineage with other bilaterians. The interrelationships of panarthropod phyla (Arthropoda, Onychophora, Tardigrada) are depicted as a polytomy because they are not currently resolved [69]. Arthropoda =Drosophila-Ixodes; Onychophora $=$ Euperipatoides; Hypsibius-Ramazzottius =Tardigrada

stage relative to each other (Fig. 6). However, the relative order of expression along the AP axis of some Wnt genes appeared to be maintained between the elongation stage and later stages during which segmental features are developing (Figs. 7, 8, 9). In other bilaterians, Wnt genes play a critical role in establishing the AP axis by promoting posterior identity, in part, by repressing anterior identity [9, 15-19]. We did not detect expression of any Wnt genes at the anterior pole of embryos at the elongation stage, besides $\mathrm{He}$-Wnt 9 and $\mathrm{He}$-Wnt 11 , genes that exhibited very broad expression patterns. Therefore it is possible that some Wnt genes are playing roles in promoting posterior identity in $H$. exemplaris and other tardigrades. Interestingly, several Wnt genes are expressed in regionalized AP patterns in the onychophoran Euperipatoides kanangrensis during early stages of segmentation [28]. Based on these regionalized patterns, it has been suggested that Wnt genes may specify segment identities in onychophorans [28]. Potentially, one or more Wnt genes are playing a role in specifying segment identities in tardigrades. Future functional studies may help resolve this issue.

\section{Wnt genes and segment polarity}

In many arthropods, $w g$, en, and $h h$, interact positively as part of a regulatory network to establish segment polarity [30-34, 43-45, 50, 52, 57]. A segmentally reiterated pattern of gene expression emerges, which includes a stripe 
of $w g$ expression positioned immediately in front of a stripe of $e n$ and $h h$ expression. Parasegmental boundaries develop between the stripes of $w g$ and the stripes of en and $h h$ expression. Parasegmental boundaries are then replaced by segmental boundaries, which develop posterior to the en and $h h$ stripes. In spiders, a different Wnt gene most likely substitutes for $w g$ to regulate segment polarity [58]. Segment polarity genes have been investigated in two onychophoran species, Euperapatoides kanangrensis $[64,65]$ and E. rowelli $[66]$. The expression patterns of the segment polarity genes in onychophorans are remarkably similar to those in arthropods. However, in contrast to arthropods, in onychophorans, Wnt genes and other segment polarity genes, besides en in E. kanangrensis, are first expressed in stripes after the earliest signs of segmentation appear $[64,66]$. Therefore, unlike in arthropods, $w g$ and other Wnt genes most likely do not play a role in segment formation in onychophorans [28, $64,66]$. Nonetheless, a conserved segment polarity network is most likely regulating intrasegmental patterning in onychophorans after segments develop [65, 66].

In $H$. exemplaris, the first signs of segmentation are the formation of endomesodermal pouches [100]. He-En expression is first detected in the ectoderm at a later stage in segmentally reiterated stripes immediately anterior to where ectodermal furrows develop between the underlying endomesodermal pouches [116]. Our results suggest that $w g$ has been lost in the tardigrade lineage. Therefore, if cWnt signaling regulates en expression to establish segment polarity in the tardigrades of our study, this interaction must be mediated though a different Wnt gene. No Wnt gene was expressed in stripes in the ectoderm at the earliest stages of the segmentation process in $H$. exemplaris (Figs. 7, 8). It is possible that cWnt signaling is not required for maintaining en expression during segment formation in Tardigrada. However, cWnt signaling could be maintaining en expression during segment formation in Tardigrada via a slightly modified mechanism. $\mathrm{He}$-Wnt4 was expressed broadly throughout the endomesodermal layer of the trunk during segment formation (Figs. 7b, 8a, b), rather than in the ectoderm as would be expected for a Wnt gene interacting with en. Nonetheless, the ligand that $\mathrm{He}$-Wnt4 encodes could be providing a signal to En expressing cells. No other Wnt gene was expressed in a segmentally reiterated pattern that would be indicative of a role in segment formation. The only Wnt gene that was expressed in a stripe-like pattern in H. exemplaris was $H e-W n t 16 B$, which was expressed later in developing legs (Fig. 9e, f', $\mathrm{f}^{\prime \prime}$ ). Although this gene is unlikely to be playing a role in segment formation, its stripe-like expression pattern may indicate a later acting segment polarity function. However, by the time that legs are visible, $\mathrm{He}$-En is no longer expressed in segmentally reiterated stripes [116]. Taken together, our results raise the interesting possibility that Wnt genes may not play a role in regulating segment polarity via regulatory interactions with en in Tardigrada. The precise developmental roles of Wnt4, Wnt16B, and other Wnt genes need to be clarified before a strong conclusion can be drawn regarding a role of $\mathrm{cWnt}$ signaling in regulating segment polarity, or the lack thereof, in Tardigrada. Additionally, other commonly conserved components of the segment polarity network, such as $h h$, need to be investigated in tardigrades. Resolving these issues is critical for determining the antiquity of the roles that the segment polarity network plays during development in Arthropoda and Onychophora.

\section{Wnt genes and leg development}

In arthropods, Wnt genes also play important roles in regulating appendage development. First, $w g$ activates expression of Distal-less $(\mathrm{Dll})$ to initiate appendage outgrowth $[46,51,117,118]$. Dll most likely also regulates appendage growth in onychophorans $[119,120] . W g$ and several other Wnt genes are expressed in a distal pattern in developing appendages in E. kanangrensis, suggesting that $w g$, and potentially other Wnt genes, may also be regulating growth via $D l l$ in onychophorans $[28,120] . D l l$ is expressed broadly across the developing legs of $H$. exemplaris, and most likely plays a role in regulating leg outgrowth in Tardigrada [82]. The tardigrades we analyzed appear to have lost $w g$. Therefore, $w g$ cannot be activating $\mathrm{Dll}$ expression in these species. It is possible that Wnt signaling is not required for activating $D l l$ expression in Tardigrada. Alternatively, one or more other Wnt genes may play this role. Wnt4 is a potential candidate for regulating $\mathrm{Dll}$ expression in tardigrades. In $\mathrm{H}$. exemplaris, this gene is expressed in the endomesodermal layer below where legs will develop in the overlying ectoderm (Fig. 8a, b). Two additional strong candidates are Wnt5 and $W n t 16 B$ (discussed in more detail below), which are both expressed strongly in developing legs (Fig. 9a-b', e, f', f"). Functional studies are required to determine whether these Wnt genes or others are required to activate $\mathrm{Dll}$ expression in Tardigrada.

Later in appendage development in arthropods, $w g$ specifies ventral appendage fate [40, 42, 46, 51, 121-123]. As with $w g$, several other Wnt genes are expressed in the developing ventral leg domain in arthropods and likely play a redundant or combinatorial role in specifying ventral appendage fate $[3,60,62,63]$. Unlike in arthropods, no Wnt genes are expressed in the ventral appendage domain in onychophorans [28]. It has been suggested that ventral expression of Wnt genes in developing appendages evolved in the arthropod lineage [28]. The tardigrades that we studied lack a $w g$ ortholog, so 
this gene cannot be playing a role in establishing ventral appendage fate in these species. However, in H. exemplaris, $\mathrm{He}-\mathrm{Wnt5}$ is expressed on the inner side of developing legs (Fig. 9a-b'). Although not definitive, we interpret the inner side of the developing legs as ventral (Fig. 5h). In this interpretation, $\mathrm{He}-\mathrm{Wnt5}$ may specify ventral appendage fate in $H$. exemplaris. Wnt5 is not expressed in a ventral stripe in developing legs of arthropods [3, 58, 63]. This may indicate that a role of Wnt5 in specifying ventral fates in developing $H$. exemplaris legs, even if present, is not homologous to the function that Wnt genes play in specifying ventral fates in arthropod appendages.

We detected expression of $\mathrm{He}-\mathrm{Wn} t 16 \mathrm{~B}$ in a stripe in each developing leg (Fig. 9e, f', f”). Although not definitive, these stripes may lay in the posterior region of each developing leg (Fig. 5g, h). The insects that have been studied most extensively, D. melanogaster and T. castaneum, lack a Wnt16 ortholog [3]. In chelicerates and the millipede Glomeris marginata, Wnt16 is expressed in the distal tip and a ventral stripe, or just in a ventral stripe, in developing legs $[3,58,63]$. The Wnt16 ortholog of the onychophoran E. kangrenesis is expressed at the distal tip and in a posterior stripe in developing legs and other appendages, besides the frontal appendage, in which it is only expressed in a posterior stripe [28]. It is possible that a posterior stripe of Wnt16 in developing appendages was inherited in tardigrades and onychophorans from the last common ancestor of these lineages. Depending on the interrelationships of the panarthropod phyla (reviewed in [69]), this ancestor could represent the last common ancestor of Panarthropoda, in which case, the absence of a posterior stripe of Wnt16 in developing arthropod appendages would represent a derived state of Arthropoda.

\section{Conclusions}

Studies of tardigrades hold the potential to help resolve the evolution of developmental mechanisms in Panarthropoda. Our study revealed interesting possibilities regarding the evolution of the roles of Wnt signaling in regulating the development of key features of Panarthropoda-segmentation and appendages. Although in many respects the anatomy of tardigrades may best represent the anatomy of the last common ancestor of Panarthropoda [124, 125], we cannot assume that developmental mechanisms in Tardigrada represent ancestral panarthropod mechanisms. In fact, studies indicate that tardigrade development is highly derived with simplification representing a common theme of developmental evolution in this lineage. For example, tardigrades have lost several Hox genes, and thus the Hox code must be simpler in modern tardigrades then it was in the last common ancestor of Panarthropoda [75]. Tardigrades are also missing a dachshund ortholog, indicating that leg patterning is simpler in modern tardigrades than it was in the last common ancestor of Panarthropoda [82]. In this study, we discovered that tardigrades have lost several Wnt genes. Other miniaturized animals are also missing several Wnt genes. In fact, Tardigrada, Nematoda, and Rotifera, which are all miniaturized animals [73, 74, 91, 92], exhibit the highest level of gene loss among animals with sequenced genomes [105]. In terms of the body plan, miniaturization is associated with anatomical simplification and reduction in cell number [73, 74, 91, 92]. Development of the simple body plans of highly miniaturized animals would not be expected to require the complex mechanisms that control development of larger animals. As developmental mechanisms, such as posterior growth or cell fate specification mechanisms that require complex combinatorial interactions, are lost in association with miniaturization, the genes that once regulated these processes may also be lost. Therefore, we propose that independent cases of extreme miniaturization in animals explain remarkable examples of convergence in terms of genome and developmental evolution.

\section{Methods}

Identifying candidate genes and phylogenetic analyses

Reciprocal BLAST searches were performed to identify candidate genes. We collected sequences from a genome assembly for $R$. varieornatus [85], and a genome assembly [71], an embryonic transcriptome assembly [126], and an adult transcriptome assembly [127] for $H$. exemplaris. We also collected sequences from genome or transcriptome assemblies for A. vaga [94], S. mediterranea [95], H. miamia [96], D. gyrociliatus [97], and E. kanangrensis [65]. All other sequences that we included in our phylogenetic analyses were publicly available in GenBank. We confirmed that candidate genes encoded predicted protein domains by CD search analysis [83]. For phylogenetic analyses, protein sequences were aligned with MUSCLE [128]. For Wnt analyses, we aligned sequences to a previously published matrix [3]. Information about sequences used in phylogenetic analyses is available in Additional file 4: S2. Alignments were trimmed using Gblocks [129, 130]. Alignments were visually inspected in Mesquite [131]. Alignments are available in Additional file 5: FASTA alignments. The LG model [132] was used for phylogenetic analyses, with an estimated proportion of invariable sites and an estimated gamma shape parameter with four substitution rate categories. Maximum likelihood analyses were performed with PhyML [133]; branch support was calculated by bootstrap (500 replicates) and the aLRT SH-like method. We produced majority rule consensus trees in Mesquite with required tree topologies set to 0.5 from three maximum 
likelihood trees [131]. Bayesian analyses were performed with MrBayes with Nchains=4 [134]. Tracer was used to diagnose convergence [135]. Posterior probabilities were calculated from 4500 trees from the posterior tree distribution.

\section{PCR and cloning}

Primers were designed from $H$. exemplaris gene sequences (sequences available upon request). GoTaq Green Master Mix (Promega) was used to amplify fragments of Wnt genes from $H$. exemplaris embryonic cDNA. Fragments were cloned into the pCR4-TOPO TA vector (Invitrogen). This strategy worked for all Wnt genes besides He-Wnt16A and He-WntA. He-Wnt16A was amplified from a single exon from genomic template. A $H e-W n t A$ fragment was synthesized by Integrated DNA Technologies. Sanger sequencing was performed by Eton Bioscience to confirm the identity of cloned or synthesized sequences.

\section{In situ hybridization and imaging}

In situ hybridization was performed by following a published protocol [136]. This protocol has been used successfully for several previous studies of tardigrade development [75, 76, 82]. After completion of the in situ hybridization protocol, embryos were mounted on slides in DAPI-Flouromount-G (SouthernBiotech). DIC and fluorescence images were captured on an Olympus FV1000 Fluoview confocal microscope. We used the fluorescence properties of the chromogenic in situ hybridization stain to capture confocal data [137]. Fluorescence data were collected using a UPlanSApo $100 \times / 1.40$ oil objective, a $405 \mathrm{~nm}$ laser to capture DAPI data, and a $635 \mathrm{~nm}$ laser using the Cy5 excitation and detection presets in the Olympus Fluoview software to capture in situ data. Brightness and contrast of confocal stacks were adjusted in ImageJ. Images were produced in the Volume Viewer plugin in ImageJ. Image levels were adjusted in Photoshop.

\footnotetext{
Abbreviations

Ad: Adineta vaga; ant: Anterior; Ap: Acyrthosiphon pisum; AP: Anteroposterior; APC: Adenomatous polyposis coli tumor suppressor; arm: Armadillo; cDNA: Complementary deoxyribonucleic acid; Ce: Caenorhabditis elegans; Cg: Crassostrea gigas; Ct: Capitella teleta; Cs: Cupiennius salei; cWnt: Canonical Wnt; DAPI: 4': 6-Diamidine-2'-phenylindole dihydrochloride; Dg: Dimorphilus gyrociliatus; DIC: Differential interference contrast; DII: Distal-less; Dm: Drosophila melanogaster; Dp: Daphnia pulex; EGF: Epidermal growth factor; en: Engrailed; Ek: Euperipatoides kanangrensis; ep1-ep4: Endomesodermal pouch 1-endomesodermal pouch 4; fg: Foregut; Fz: Frizzled; Gm: Glomeris marginata; He: Hypsibius exemplaris; hh: Hedgehog; Hm: Hofstenia miamia; Hs: Homo sapiens; Is: Ixodes scapularis; 11-14: Leg 1-leg 4; Lrp: Low-density lipoprotein receptor; Mm: Mus musculus; nt: Nucleotide; Ob: Octopus bimaculoides; pan: Pangolin; PCR: Polymerase chain reaction; Pd: Platynereis dumerilii; PD: Proximodistal; pos: Posterior; Pt: Parasteatoda tepidariorum; Rv: Ramazzotius varieornatus; sgg: Shaggy; Sm: Schmidtea mediterranea; 1 -t4: Trunk segment 1-trunk segment
}

4; Tc: Tribolium castaneum; wg: Wingless; XI: Xenopus laevis; Zn: Zootermopsis nevadensis.

\section{Supplementary Information}

The online version contains supplementary material available at https://doi. org/10.1186/s12862-021-01954-y.

Additional file 1: Figure S1. Majority rule consensus tree of Wnt ligands. This tree is the same tree shown in Fig. 1, but includes branch length information. See Fig. 1 caption for additional details.

Additional file 2: S1. Results of reciprocal BLAST searches for orthologs of Arrow/ LRP5/LRP6. D. melanogaster Arrow sequence was used to query protein databases. The top ten matches were analyzed by reciprocal BLAST search against $D$. melanogaster reference proteins. The source of the Subject sequences is provided. For Subject sequences that are not available in GenBank, we provide a link to the source of the data, the ID of each sequence in the data set from which it was recovered, and each sequence.

Additional file 3: Figure S2. In situ hybridization results for Wnt genes that were expressed across entire embryos, were very weakly expressed, or exhibited inconsistent expression patterns at one or more developmental stages in H. exemplaris. All images are DIC micrographs. Purple staining represents gene expression. Anterior is towards the top. a-c Wnt2 expression was weak at all stages investigated except for stage 11. d Wnt4 expression was weak during stage 14. $\mathbf{e - h}$ Wnt9 was broadly expressed during all stages investigated, but may have been more highly expressed in the endomesodermal layer. $\mathbf{e - g}$ Left panels are $1 / 2$ probe concentration. i-I Wnt11 expression was detected throughout the embryo but was strongest at the posteriormost region. $\mathbf{m}-\mathbf{p}$ Wnt16A expression was weak or undetectable as all stages investigated.

Additional file 4: S2. Sources of sequences in phylogenetic analyses in this study. For sequences that are not available in GenBank, we provide a link to the source of the data, the ID of each sequence in the data set from which it was recovered, and each sequence. For the Wnt analyses, all sequences besides those from tardigrades and Euperipatoides kanangrensis were part of a previously published matrix [3]. GenBank Accession numbers for tardigrade Wnt and Frizzled sequences are available in Table 1.

Additional file 5: FASTA alignments. Alignments used in phylogenetics analyses in this study.

\section{Acknowledgements}

We thank Ralf Janssen and Chema Martin for helpful comments that improved the quality of our manuscript. FWS lab members Nichole Wyman, Kennedi Light, Tatiana Baia, and Taylor Harrison provided helpful comments on this work.

\section{Authors' contributions}

FWS designed the study, performed wet lab work and bioinformatics analyses, and made figures. RAC performed wet lab work, collected confocal data, and made figures. FWS and RAC wrote the first draft of the manuscript. MG collected confocal data and performed wet lab work. ZKS performed wet lab work. BA, CR, ZKS performed bioinformatics analyses. FWS, RAC, and MG edited the manuscript. All authors have read and approved the manuscript.

\section{Funding}

This material is based upon work supported by the National Science Foundation under Grant No. 1951257 to FWS. Additional funding was provided by startup funds to FWS from the University of North Florida. Funding sources were not involved in the design, analysis, and interpretation of the study, or in writing the manuscript.

\section{Availability of data and materials}

All sequence data analyzed in this study are publicly available. H. exemplaris sequence data are from NCBI BioProject PRJNA360553 [71]. R. varieornatus sequence data are from NCBI BioProject PRJDB4588 [85]. GenBank accession numbers for other sequences that we analyzed are available in Additional 
file 2: S1 and Additional file 4: S2. Links to data sources and sequences are available in Additional file 2: S1 and Additional file 4: S2 in cases where sequences do not have GenBank accession numbers.

\section{Declarations}

Ethics approval and consent to participate

Studies of tardigrades do not require ethics approval or consent to participate.

\section{Consent for publication}

Not applicable.

\section{Competing interests}

The authors declare that they have no competing interests.

Received: 16 October 2021 Accepted: 9 December 2021 Published online: 27 December 2021

\section{References}

1. Croce JC, McClay DR. Evolution of the Wnt pathways. Methods Mol Biol. 2008;469:3-18.

2. Cho S, Vallès Y, Giani VC Jr, Seaver EC, Weisblat DA. Evolutionary dynamics of the Wnt gene family: a lophotrochozoan perspective. Mol Biol Evol. 2010;27:1645-58.

3. Janssen R, Le Gouar M, Pechmann M, Poulin F, Bolognesi R, Schwager EE, Hopfen C, Colbourne JK, Budd GE, Brown SJ. Conservation, loss, and redeployment of Wnt ligands in protostomes: implications for understanding the evolution of segment formation. BMC Evol Biol. 2010;10:374.

4. Holstein TW. The evolution of the Wnt pathway. CSH Perspect Biol. 2012;4(7):a007922.

5. Liu J, Xu F, Ji P, Li L, Zhang G. Evolutionary dynamics of the Wnt gene family: implications for lophotrochozoans. J Oceanol Limnol. 2018;36:1720-30.

6. Hogvall M, Vellutini BC, Martín-Durán JM, Hejnol A, Budd GE, Janssen R. Embryonic expression of priapulid Wnt genes. Dev Genes Evol. 2019;229:125-35.

7. Ryan JF, Baxevanis AD. Hox, Wnt, and the evolution of the primary body axis: insights from the early-divergent phyla. Biol Direct. 2007;2:37.

8. Holstein TW. Wnt signaling in cnidarians. In: Vincanr E, editor. Methods in molecular biology. Tototwa: Humana Press; 2008. p. 47-54.

9. Petersen $C P$, Reddien PW. Wnt signaling and the polarity of the primary body axis. Cell. 2009;139:1056-68.

10. Jager M, Dayraud C, Mialot A, Queinnec E, Le Guyader H, Manuel M. Evidence for involvement of Wnt signalling in body polarities, cell proliferation, and the neuro-sensory system in an adult ctenophore. PLoS ONE. 2013;8(12):e84363.

11. Babonis LS, Martindale MQ. Phylogenetic evidence for the modular evolution of metazoan signalling pathways. Philos Trans R Soc B. 2017;372(1713):20150477.

12. DuBuc TQ, Stephenson TB, Rock AQ, Martindale MQ. Hox and Wnt pattern the primary body axis of an anthozoan cnidarian before gastrulation. Nat Commun. 2018;9:1-12.

13. Reid PJW, Matveev E, McClymont A, Posfai D, Hill AL, Leys SP. Wnt signaling and polarity in freshwater sponges. BMC Evol Biol. 2018;18:12.

14. Wijesena N, Martindale MQ. Reengineering the primary body axis by ectopic cWnt signaling. Curr Biol. 2018;28:R206-7.

15. De Robertis EM. Wnt signaling in axial patterning and regeneration: lessons from planaria. Sci Signal. 2010;3(127):pe21.

16. Fu J, Posnien N, Bolognesi R, Fischer TD, Rayl P, Oberhofer G, Kitzmann P, Brown SJ, Bucher G. Asymmetrically expressed axin required for anterior development in Tribolium. Proc Natl Acad Sci USA. 2012;109:7782-6.

17. Prühs R, Beermann A, Schröder R. The roles of the Wnt-antagonists axin and Lrp4 during embryogenesis of the red flour beetle Tribolium castaneum. J Dev Biol. 2017;5(4):10.

18. Ansari S, Troelenberg N, Richter T, Bucher G, Klingler M. Double abdomen in a short-germ insect: Zygotic control of axis formation revealed in the beetle Tribolium castaneum. Proc Natl Acad Sci USA. 2018;115:1819-24.

19. Darras S, Fritzenwanker JH, Uhlinger KR, Farrelly E, Pani AM, Hurley IA, Norris RP, Osovitz M, Terasaki M, Wu M. Anteroposterior axis patterning by early canonical Wnt signaling during hemichordate development. PLOS Biol. 2018;16(1):e2003698.

20. Martin BL, Kimelman D. Wnt signaling and the evolution of embryonic posterior development. Curr Biol. 2009;19:R215-9.

21. McGregor AP, Pechmann M, Schwager EE, Damen WG. An ancestral regulatory network for posterior development in arthropods. Commun Integr Biol. 2009;2:174-6.

22. Steventon B, Duarte F, Lagadec R, Mazan S, Nicolas J, Hirsinger E. Species-specific contribution of volumetric growth and tissue convergence to posterior body elongation in vertebrates. Development. 2016;143:1732-41.

23. Sarrazin AF, Peel AD, Averof M. A segmentation clock with two-segment periodicity in insects. Science. 2012;336:338-41.

24. Auman T, Vreede BM, Weiss A, Hester SD, Williams TA, Nagy LM, Chipman AD. Dynamics of growth zone patterning in the milkweed bug Oncopeltus fasciatus. Development. 2017;144:1896-905.

25. Cepeda RE, Pardo RV, Macaya CC, Sarrazin AF. Contribution of cell proliferation to axial elongation in the red flour beetle Tribolium castaneum. PLOS ONE. 2017;12(10):e0186159.

26. Williams TA, Nagy LM. Linking gene regulation to cell behaviors in the posterior growth zone of sequentially segmenting arthropods. Arthropod Struct Dev. 2017:46:380-94.

27. Fritzenwanker JH, Uhlinger KR, Gerhart J, Silva E, Lowe CJ. Untangling posterior growth and segmentation by analyzing mechanisms of axis elongation in hemichordates. Proc Natl Acad Sci USA. 2019;116:8403-8.

28. Hogvall M, Schönauer A, Budd GE, McGregor AP, Posnien N, Janssen R. Analysis of the Wnt gene repertoire in an onychophoran provides new insights into the evolution of segmentation. EvoDevo. 2014;5(1):1-15.

29. Constantinou SJ, Duan N, Nagy LM, Chipman AD, Williams TA. Elongation during segmentation shows axial variability, low mitotic rates, and synchronized cell cycle domains in the crustacean, Thamnocephalus platyurus. EvoDevo. 2020;11(1):1.

30. Lee PN, Pang K, Matus DQ, Martindale MQ. A WNT of things to come: evolution of Wnt signaling and polarity in cnidarians. Semin Cell Dev Biol. 2006;17(2):157-67.

31. DiNardo S, Sher E, Heemskerk-Jongens J, Kassis JA, O'Farrell PH. Twotiered regulation of spatially patterned engrailed gene expression during Drosophila embryogenesis. Nature. 1988;332:604-9.

32. Arias AM, Baker NE, Ingham PW. Role of segment polarity genes in the definition and maintenance of cell states in the Drosophila embryo. Development. 1988;103:157-70.

33. Lee JJ, von Kessler DP, Parks S, Beachy PA. Secretion and localized transcription suggest a role in positional signaling for products of the segmentation gene hedgehog. Cell. 1992;71:33-50.

34. Larsen CW, Hirst E, Alexandre C, Vincent J. Segment boundary formation in Drosophila embryos. Development. 2003;130:5625-35.

35. Biffar L, Stollewerk A. Conservation and evolutionary modifications of neuroblast expression patterns in insects. Dev Biol. 2014;388:103-16.

36. Simcox AA, Roberts I, Hersperger E, Gribbin MC, Shearn A, Whittle JRS. Imaginal discs can be recovered from cultured embryos mutant for the segment-polarity genes engrailed, naked and patched but not from wingless. Development. 1989;107:715-22.

37. Diaz-Benjumea FJ, Cohen B, Cohen SM. Cell interaction between compartments establishes the proximal-distal axis of Drosophila legs. Nature. 1994;372:175-9.

38. Campbell G, Tomlinson A. Initiation of the proximodistal axis in insect legs. Development. 1995;121:619-28.

39. Lecuit T, Cohen SM. Proximal-distal axis formation in the Drosophila leg. Nature. 1997;388:139-45.

40. Brook WJ, Cohen SM. Antagonistic interactions between wingless and decapentaplegic responsible for dorsal-ventral pattern in the Drosophila leg. Science. 1996;273:1373-7.

41. Jiang J, Struhl G. Complementary and mutually exclusive activities of decapentaplegic and wingless organize axial patterning during Drosophila leg development. Cell. 1996;86:401-9. 
42. Theisen H, Haerry TE, O'Connor MB, Marsh JL. Developmental territories created by mutual antagonism between Wingless and Decapentaplegic. Development. 1996;122:3939-48.

43. Oppenheimer DI, MacNicol AM, Patel NH. Functional conservation of the wingless-engrailed interaction as shown by a widely applicable baculovirus misexpression system. Curr Biol. 1999;9:1288-96.

44. Damen WG. Parasegmental organization of the spider embryo implies that the parasegment is an evolutionary conserved entity in arthropod embryogenesis. Development. 2002;129:1239-50.

45. Janssen R, Prpic N, Damen WG. Gene expression suggests decoupled dorsal and ventral segmentation in the millipede Glomeris marginata (Myriapoda: Diplopoda). Dev Biol. 2004;268:89-104.

46. Miyawaki K, Mito T, Sarashina I, Zhang H, Shinmyo Y, Ohuchi H, Noji S. Involvement of Wingless/Armadillo signaling in the posterior sequential segmentation in the cricket, Gryllus bimaculatus (Orthoptera), as revealed by RNAi analysis. Mech Dev. 2004;121:119-30.

47. Prpic N. Homologs of wingless and decapentaplegic display a complex and dynamic expression profile during appendage development in the millipede Glomeris marginata (Myriapoda: Diplopoda). Front Zool. 2004;1:1-12.

48. Angelini DR, Kaufman TC. Functional analyses in the milkweed bug Oncopeltus fasciatus (Hemiptera) support a role for Wnt signaling in body segmentation but not appendage development. Dev Biol. 2005:283:409-23.

49. Peel AD, Chipman AD, Akam M. Arthropod segmentation: beyond the Drosophila paradigm. Nat Rev Genet. 2005;6:905-16.

50. Janssen R, Budd GE, Damen WG, Prpic N. Evidence for Wg-independent tergite boundary formation in the millipede Glomeris marginata. Dev Genes Evol. 2008:218:361-70.

51. Grossmann D, Scholten J, Prpic N. Separable functions of wingless in distal and ventral patterning of the Tribolium leg. Dev Genes Evol. 2009;219:469-79.

52. Janssen R. Segment polarity gene expression in a myriapod reveals conserved and diverged aspects of early head patterning in arthropods. Dev Genes Evol. 2012;222:299-309.

53. Jockusch EL, Smith FW. Hexapoda: comparative aspects of later embryogenesis and metamorphosis. In: Wanninger A, editor. Evolutionary developmental biology of invertebrates 5. Vienna: Springer; 2015. p. 111-208.

54. Setton EV, Sharma PP. Cooption of an appendage-patterning gene cassette in the head segmentation of arachnids. Proc Natl Acad Sci USA. 2018;115:E3491-500.

55. Angelini DR, Kaufman TC. Insect appendages and comparative ontogenetics. Dev Biol. 2005;286:57-77.

56. Chipman AD. The evolution of the gene regulatory networks patterning the Drosophila Blastoderm. Gene Regul Netw. 2020;139:297.

57. Lim J, Choe CP. Functional analysis of engrailed in Tribolium segmentation. Mech Dev. 2020;161:103594.

58. Janssen R, Pechmann M, Turetzek N. A chelicerate Wnt gene expression atlas: novel insights into the complexity of arthropod Wnt-patterning. EvoDevo. 2021;12(1):1-27.

59. Bolognesi R, Farzana L, Fischer TD, Brown SJ. Multiple Wnt genes are required for segmentation in the short-germ embryo of Tribolium castaneum. Curr Biol. 2008;18:1624-9.

60. Bolognesi R, Beermann A, Farzana L, Wittkopp N, Lutz R, Balavoine G, Brown SJ, Schröder R. Tribolium Wnts: evidence for a larger repertoire in insects with overlapping expression patterns that suggest multiple redundant functions in embryogenesis. Dev Genes Evol. 2008:218:193-202.

61. Murat S, Hopfen C, McGregor AP. The function and evolution of Wnt genes in arthropods. Arthropod Struct Dev. 2010;39:446-52.

62. Hayden L, Arthur W. The centipede Strigamia maritima possesses a large complement of Wnt genes with diverse expression patterns. Evol Dev. 2014:16:127-38.

63. Janssen R, Posnien N. Identification and embryonic expression of Wnt2, Wnt4, Wnt5 and Wnt9 in the millipede Glomeris marginata (Myriapoda: Diplopoda). Gene Expr Patterns. 2014;14:55-61.

64. Eriksson BJ, Tait NN, Budd GE, Akam M. The involvement of engrailed and wingless during segmentation in the onychophoran Euperipatoides kanangrensis (Peripatopsidae: Onychophora) (Reid 1996). Dev Genes Evol. 2009:219:249-64
65. Janssen R, Budd GE. Deciphering the onychophoran 'segmentation gene cascade': gene expression reveals limited involvement of pair rule gene orthologs in segmentation, but a highly conserved segment polarity gene network. Dev Biol. 2013;382:224-34.

66. Franke FA, Mayer G. Controversies surrounding segments and parasegments in Onychophora: insights from the expression patterns of four "segment polarity genes" in the peripatopsid Euperipatoides rowelli. PLOS ONE. 2014;9(12):e114383.

67. Dunn CW, Hejnol A, Matus DQ, Pang K, Browne WE, Smith SA, Seaver E, Rouse GW, Obst M, Edgecombe GD. Broad phylogenomic sampling improves resolution of the animal tree of life. Nature. 2008;452:745-9.

68. Campbell LI, Rota-Stabelli O, Edgecombe GD, Marchioro T, Longhorn SJ, Telford MJ, Philippe H, Rebecchi L, Peterson KJ, Pisani D. MicroRNAs and phylogenomics resolve the relationships of Tardigrada and suggest that velvet worms are the sister group of Arthropoda. Proc Natl Acad Sci USA. 2011:108:15920-4.

69. Giribet G, Edgecombe GD. Current understanding of Ecdysozoa and its internal phylogenetic relationships. Integr Comp Biol. 2017;57:455-66.

70. Janssen R. A molecular view of onychophoran segmentation. Arthropod Struct Dev. 2017:46:341-53.

71. Yoshida Y, Koutsovoulos G, Laetsch DR, Stevens L, Kumar S, Horikawa DD, Ishino K, Komine S, Kunieda T, Tomita M. Comparative genomics of the tardigrades Hypsibius dujardini and Ramazzottius varieornatus. PLoS Biol. 2017;15(7):e2002266.

72. Smith MR, Ortega-Hernández J. Hallucigenia's onychophoran-like claws and the case for Tactopoda. Nature. 2014;514:363-6.

73. Schmidt-Rhaesa A. Tardigrades—are they really miniaturized dwarfs? Zool Anz. 2001;240:549-55.

74. Gross V, Treffkorn S, Reichelt J, Epple L, Lüter C, Mayer G. Miniaturization of tardigrades (water bears): morphological and genomic perspectives. Arthropod Struct Dev. 2019:48:12-9.

75. Smith FW, Boothby TC, Giovannini I, Rebecchi L, Jockusch EL, Goldstein B. The compact body plan of tardigrades evolved by the loss of a large body region. Curr Biol. 2016;26:224-9.

76. Smith FW, Cumming M, Goldstein B. Analyses of nervous system patterning genes in the tardigrade Hypsibius exemplaris illuminate the evolution of panarthropod brains. EvoDevo. 2018;9(1):19.

77. Smith FW, Goldstein B. Segmentation in Tardigrada and diversification of segmental patterns in Panarthropoda. Arthropod Struct Dev. 2017:46:328-40.

78. Guil N, Jørgensen A, Kristensen R. An upgraded comprehensive multilocus phylogeny of the Tardigrada tree of life. Zool Scr. 2019;48:120-37.

79. Hejnol A, Schnabel R. The eutardigrade Thulinia stephaniae has an indeterminate development and the potential to regulate early blastomere ablations. Development. 2005;132:1349-61.

80. Gross V, Mayer G. Neural development in the tardigrade Hypsibius dujardini based on anti-acetylated a-tubulin immunolabeling. EvoDevo. 2015;6(1):12.

81. Gross V, Minich I, Mayer G. External morphogenesis of the tardigrade Hypsibius dujardini as revealed by scanning electron microscopy. J Morphol. 2017:278:563-73.

82. Game M, Smith FW. Loss of intermediate regions of perpendicular body axes contributed to miniaturization of tardigrades. Proc R Soc B. 1931;2020(287):20201135.

83. Marchler-Bauer A, Derbyshire MK, Gonzales NR, Lu S, Chitsaz F, Geer LY, Geer RC, He J, Gwadz M, Hurwitz DI. CDD: NCBI's conserved domain database. Nucleic Acids Res. 2015;43(D1):D222-6.

84. Riddiford N, Olson PD. Wnt gene loss in flatworms. Dev Genes Evol. 2011;221(4):187.

85. Hashimoto T, Horikawa DD, Saito Y, Kuwahara H, Kozuka-Hata H, Shin T, Minakuchi Y, Ohishi K, Motoyama A, Aizu T. Extremotolerant tardigrade genome and improved radiotolerance of human cultured cells by tardigrade-unique protein. Nat Commun. 2016;7:12808.

86. Bastin BR, Chou H, Pruitt MM, Schneider SQ. Structure, phylogeny, and expression of the frizzled-related gene family in the lophotrochozoan annelid Platynereis dumerilii. EvoDevo. 2015;6(1):1-24.

87. Janssen R, Schönauer A, Weber M, Turetzek N, Hogvall M, Goss GE, Patel $\mathrm{NH}, \mathrm{McGregor}$ AP, Hilbrant M. The evolution and expression of panarthropod frizzled genes. Front Ecol Evol. 2015;3:96.

88. Wehrli M, Dougan ST, Caldwell K, O'Keefe L, Schwartz S, VaizelOhayon D, Schejter E, Tomlinson A, DiNardo S. arrow encodes an 
LDL-receptor-related protein essential for Wingless signalling. Nature. 2000;407:527-30

89. Schweizer $L$, Varmus H. Wnt/Wingless signaling through $\beta$-catenin requires the function of both LRP/Arrow and frizzled classes of receptors. BMC Cell Biol. 2003;4(1):1-11.

90. Baig-Lewis S, Peterson-Nedry W, Wehrli M. Wingless/Wnt signal transduction requires distinct initiation and amplification steps that both depend on Arrow/LRP. Dev Biol. 2007;306:94-111.

91. Giere O. Meiobenthology: the microscopic motile fauna of aquatic sediments. Berlin: Springer Science \& Business Media; 2008.

92. Rundell RJ, Leander BS. Masters of miniaturization: convergent evolution among interstitial eukaryotes. BioEssays. 2010;32:430-7.

93. Srivastava M, Mazza-Curll KL, van Wolfswinkel JC, Reddien PW. Whole-body acoel regeneration is controlled by Wnt and Bmp-Admp signaling. Curr Biol. 2014;24:1107-13.

94. Flot J, Hespeels B, Li X, Noel B, Arkhipova I, Danchin EG, Hejnol A, Henrissat B, Koszul R, Aury J. Genomic evidence for ameiotic evolution in the bdelloid rotifer Adineta vaga. Nature. 2013;500:453-7.

95. Grohme MA, Schloissnig S, Rozanski A, Pippel M, Young GR, Winkler S, Brandl H, Henry I, Dahl A, Powell S. The genome of Schmidtea mediterranea and the evolution of core cellular mechanisms. Nature. 2018;554:56-61.

96. Gehrke AR, Neverett E, Luo Y, Brandt A, Ricci L, Hulett RE, Gompers A, Ruby JG, Rokhsar DS, Reddien PW. Acoel genome reveals the regulatory landscape of whole-body regeneration. Science. 2019. https:// doi.org/10.1126/science.aau6173.

97. Martín-Durán JM, Vellutini BC, Marlétaz F, Cetrangolo V, Cvetesic N, Thiel D, Henriet S, Grau-Bové X, Carrillo-Baltodano AM, Gu W. Conservative route to genome compaction in a miniature annelid. Nat Ecol Evol. 2021;5:231-42.

98. Pascual-Carreras E, Sureda-Gómez M, Barrull-Mascaró R, Jordà N, Gelabert M, Coronel-Córdoba P, Saló E, Adell T. WNT-FRIZZLED-LRP5/6 signaling mediates posterior fate and proliferation during planarian regeneration. Genes. 2021;12(1):101.

99. Phillips BT, Kimble J. A new look at TCF and $\beta$-catenin through the lens of a divergent C. elegans Wnt pathway. Dev Cell. 2009;17:27-34.

100. Gabriel WN, McNuff R, Patel SK, Gregory TR, Jeck WR, Jones CD, Goldstein B. The tardigrade Hypsibius dujardini, a new model for studying the evolution of development. Dev Biol. 2007;312:545-59.

101. Steinmetz PR, Urbach R, Posnien N, Eriksson J, Kostyuchenko RP, Brena C, Guy K, Akam M, Bucher G, Arendt D. Six3 demarcates the anterior-most developing brain region in bilaterian animals. EvoDevo. 2010;1(1):1-9.

102. Treffkorn S, Kahnke L, Hering L, Mayer G. Expression of NK cluster genes in the onychophoran Euperipatoides rowelli: implications for the evolution of NK family genes in nephrozoans. EvoDevo. 2018;9(1):1-32.

103. Ferrier DE, Minguillon C. Evolution of the Hox/ParaHox gene clusters. Int J Dev Biol. 2003;47:605-11.

104. MacDonald BT, He X. Frizzled and LRP5/6 receptors for Wnt/ $\beta$-catenin signaling. CSH Perspect Biol. 2012;4(12):a007880.

105. Guijarro-Clarke C, Holland PW, Paps J. Widespread patterns of gene loss in the evolution of the animal kingdom. Nat Ecol Evol. 2020;4:519-23.

106. Arimoto A, Hikosaka-Katayama T, Hikosaka A, Tagawa K, Inoue T, Ueki T, Yoshida M, Kanda M, Shoguchi E, Hisata K. A draft nuclear-genome assembly of the acoel flatworm Praesagittifera naikaiensis. GigaScience. 2019;8(4):giz023.

107. Ramirez A. Heads or tails? Regulation of Wnt signaling and axial identity establishment during whole-body regeneration in the acoel worm Hofstenia miamia. Doctoral Dissertation. 2020.

108. Pruitt MM, Letcher EJ, Chou H, Bastin BR, Schneider SQ. Expression of the wnt gene complement in a spiral-cleaving embryo and trochophore larva. Int J Dev Biol. 2014;58:563-73.

109. McGregor AP, Pechmann M, Schwager EE, Feitosa NM, Kruck S, Aranda M, Damen WG. Wnt8 is required for growth-zone establishment and development of opisthosomal segments in a spider. Curr Biol. 2008:18:1619-23.

110. Chesebro JE, Pueyo JI, Couso JP. Interplay between a Wnt-dependent organiser and the Notch segmentation clock regulates posterior development in Periplaneta americana. Biol Open. 2013;2:227-37.
111. Jacobs DK, Hughes NC, Fitz-Gibbon ST, Winchell CJ. Terminal addition, the Cambrian radiation and the Phanerozoic evolution of bilaterian form. Evol Dev. 2005:7:498-514.

112. Gold DA, Runnegar B, Gehling JG, Jacobs DK. Ancestral state reconstruction of ontogeny supports a bilaterian affinity for Dickinsonia. Evol Dev. 2015;17(6):315-24.

113. Pinson Kl, Brennan J, Monkley S, Avery BJ, Skarnes WC. An LDLreceptor-related protein mediates Wnt signalling in mice. Nature. 2000;407:535-8.

114. Bolognesi R, Fischer TD, Brown SJ. Loss of Tc-arrow and canonical Wnt signaling alters posterior morphology and pair-rule gene expression in the short-germ insect, Tribolium castaneum. Dev Genes Evol. 2009;219:369-75.

115. Setton EV, Sharma PP. A conserved role for arrow in posterior axis patterning across Arthropoda. Dev Biol. 2021;475:91-105.

116. Gabriel WN, Goldstein B. Segmental expression of Pax3/7 and Engrailed homologs in tardigrade development. Dev Genes Evol. 2007;217:421-33.

117. Cohen B, Simcox AA, Cohen SM. Allocation of the thoracic imaginal primordia in the Drosophila embryo. Development. 1993:117:597-608.

118. Kubota K, Goto S, Hayashi S. The role of Wg signaling in the patterning of embryonic leg primordium in Drosophila. Dev Biol. 2003;257:117-26.

119. Panganiban G, Irvine SM, Lowe C, Roehl H, Corley LS, Sherbon B, Grenier $J \mathrm{~J}$, Fallon JF, Kimble J, Walker M. The origin and evolution of animal appendages. Proc Natl Acad Sci USA. 1997;94:5162-6.

120. Janssen R, Eriksson BJ, Budd GE, Akam M, Prpic N. Gene expression patterns in an onychophoran reveal that regionalization predates limb segmentation in pan-arthropods. Evol Dev. 2010;12:363-72.

121. Struhl G, Basler K. Organizing activity of wingless protein in Drosophila. Cell. 1993;72:527-40.

122. Ober KA, Jockusch EL. The roles of wingless and decapentaplegic in axis and appendage development in the red flour beetle, Tribolium castaneum. Dev Biol. 2006;294:391-405.

123. Prpic N, Janssen R, Wigand B, Klingler M, Damen WG. Gene expression in spider appendages reveals reversal of exd/hth spatial specificity, altered leg gap gene dynamics, and suggests divergent distal morphogen signaling. Dev Biol. 2003;264:119-40.

124. Ortega-Hernández J, Janssen R, Budd GE. Origin and evolution of the panarthropod head-a palaeobiological and developmental perspective. Arthropod Struct Dev. 2017:46:354-79.

125. Park TS, Kihm J, Woo J, Park C, Lee WY, Smith MP, Harper DA, Young F, Nielsen AT, Vinther J. Brain and eyes of Kerygmachela reveal protocerebral ancestry of the panarthropod head. Nat Commun. 2018;9:1-7.

126. Levin M, Anavy L, Cole AG, Winter E, Mostov N, Khair S, Senderovich N, Kovalev E, Silver DH, Feder M. The mid-developmental transition and the evolution of animal body plans. Nature. 2016;531:637-41.

127. Boothby TC, Tapia H, Brozena AH, Piszkiewicz S, Smith AE, Giovannini I, Rebecchi L, Pielak GJ, Koshland D, Goldstein B. Tardigrades use intrinsically disordered proteins to survive desiccation. Mol Cell. 2017;65:975-84.

128. Edgar RC. MUSCLE: multiple sequence alignment with high accuracy and high throughput. Nucleic Acids Res. 2004;32:1792-7.

129. Castresana J. Selection of conserved blocks from multiple alignments for their use in phylogenetic analysis. Mol Biol Evol. 2000;17:540-52.

130. Dereeper A, Guignon V, Blanc G, Audic S, Buffet S, Chevenet F, Dufayard J, Guindon S, Lefort V, Lescot M. Phylogeny.fr: robust phylogenetic analysis for the non-specialist. Nucleic Acids Res. 2008;36(suppl_2):W465-9.

131. Maddison W, Maddison D. Mesquite: a modular system for evolutionary analysis. Version 3.51. 2018. See www.mesquiteproject.org.

132. Le SQ, Gascuel O. An improved general amino acid replacement matrix Mol Biol Evol. 2008;25:1307-20.

133. Guindon S, Dufayard J, Lefort V, Anisimova M, Hordijk W, Gascuel O. New algorithms and methods to estimate maximum-likelihood phylogenies: assessing the performance of PhyML 3.0. Syst Biol. 2010;59:307-21.

134. Huelsenbeck JP, Ronquist F. Bayesian analysis of molecular evolution using MrBayes. In: Nielsen R, editor. Statistical methods in molecular evolution. New York: Springer-Verlag; 2005. p. 183-226.

135. Rambaut A, Drummond AJ, Xie D, Baele G, Suchard MA. Posterior summarization in Bayesian phylogenetics using Tracer 1.7. Syst Biol. 2018:67:901. 
136. Smith FW. Embryonic in situ hybridization for the tardigrade Hypsibius exemplaris. Cold Spring Harb Protoc. 2018. https://doi.org/10.1101/pdb. prot102350.

137. Trinh LA, McCutchen MD, Bonner-Fraser M, Fraser SE, Bumm LA, McCauley DW. Fluorescent in situ hybridization employing the conventional NBT/BCIP chromogenic stain. Biotechniques. 2007:42:756-9.

\section{Publisher's Note}

Springer Nature remains neutral with regard to jurisdictional claims in published maps and institutional affiliations.

- fast, convenient online submission

- thorough peer review by experienced researchers in your field

- rapid publication on acceptance

- support for research data, including large and complex data types

- gold Open Access which fosters wider collaboration and increased citations

- maximum visibility for your research: over 100M website views per year

At $\mathrm{BMC}$, research is always in progress.

Learn more biomedcentral.com/submissions 